\title{
EL DERECHO DE REEMBOLSO EN LA FASE EXTRAJUDICIAL EN EL MARCO DE LA GARANTÍA LEGAL
}

\section{THE RIGHT OF REFUND IN THE EXTRAJUDICIAL PHASE WITHIN THE FRAMEWORK OF THE LEGAL GUARANTEE}

Marcos Manque Jaramillo*

\section{RESUMEN}

En este artículo se analiza cómo opera el derecho de reembolso en la fase extrajudicial, en caso de disconformidad material del bien, en la compraventa de consumo. Mediante un estudio endémico realizado por una entrevista-cuestionario en tiendas de venta masiva de productos de la comuna de Santiago se comprueba la reticencia a otorgarlo ante el requerimiento de este derecho por parte del comprador, haciendo prevalecer en su lugar otros mecanismos más convenientes para el vendedor.

Palabras clave: derecho de reembolso; consumidor; garantía legal; compraventa.

\section{AbStract}

This article analyzes how the right of reimbursement operates in the extrajudicial phase, in the case of non-conformity of the goods in the consumer sales. Through an endemic study carried out by an interview-questionnaire in some stores in Santiago, the reluctance to grant it to the requirement of this right by the buyer is verified, making other mechanisms prevail instead more convenient for the seller.

Keywords: right of reimbursement; consumer; legal guarantee; trading.

* Licenciado en Ciencias Jurídicas y Sociales Universidad Alberto Hurtado. Dirección postal: Almirante Barroso 10, Santiago. Correo electrónico: manquefj@gmail.com. Artículo recibido el 5 de agosto de 2019 y aceptado para su publicación el 25 de abril de 2020.

La presente publicación corresponde, con alguna modificación, a la tesis para optar al grado de Licenciado en Ciencias Jurídicas y Sociales, y se enmarca en el proyecto Fondecyt 1171251, cuyo investigador responsable es el profesor Alfredo Ferrante. 


\section{INTRODUCCIÓN}

En el contexto de las relaciones existentes entre consumidores y proveedores de bienes de consumo, surgen conflictos muy relevantes para el derecho, ya que un rasgo esencial de dichas relaciones es la desigualdad de posiciones en que se encuentran los distintos actores participantes ${ }^{1}$. Tan central es, que a raíz de ella el Ejecutivo en 1991 comienza una serie de debates legislativos, que culminan ${ }^{2}$ en 1997 con la promulgación de la Ley n. ${ }^{\circ}$ 19496, que Establece Normas sobre Protección de los Derechos de los Consumidores. La premisa de dicha normativa resulta de la necesidad de protección que requieren los consumidores en el marco de sus relaciones de consumo ${ }^{3}$.

Pues bien, en la LPC destaca el sistema de protección civil denominado como garantía legal ${ }^{4}$, dentro de la cual se encuentra el art. 20, que consagra la denominada triple opción ${ }^{5}$, esto es una protección jurídica que tiene el consumidor frente a los vicios de las $\operatorname{cosas}^{6}$, que le permite optar por la reposición, reparación o devolución de la cantidad pagada ${ }^{7}$, en adelante reembolso.

La especial atención en el reembolso en este trabajo, deriva de que de las tres opciones que otorga la garantía legal, la devolución de la cantidad pagada, consiste en la facultad que tiene el consumidor de resolver el contrato, pues este no quiere seguir vinculado con el proveedor y pre-

${ }^{1}$ Biblioteca del Congreso Nacional de Chile (1998). En dicha ocasión el Presidente expresó: “...es responsabilidad del Estado cautelar en forma especial los intereses de los grupos o sectores no organizados, entre los que se cuentan los consumidores. A estos se les debe proporcionar un marco legal que consagre expresamente sus derechos y la forma de ejercerlos con eficacia, así como mecanismos que faciliten su rol activo en una economía de mercado, de modo de impedir eventuales abusos que se deriven de la carencia de un ordenamiento jurídico adecuado", p. 5.

${ }^{2} \mathrm{Si}$ bien fue un intento por regular de "forma sistemática los aspectos más relevantes de la protección de los consumidores", esta debió ser profundamente reformada. SANDOVAL (2009), p. 128.

${ }^{3}$ Rodríguez (2015), p. 6.

${ }^{4}$ Barrientos (2014), p. 58. Cuya principal función es la de regular la responsabilidad civil del vendedor BARRIENTOS (2016), p. 7.

${ }^{5}$ Cabe la aclaración de que la garantía legal no se agota en esta triple opción, sino que la ley distingue distintos tipos de disposiciones: a) normas que tipifican y sancionan infracciones, como las descritas en los artículos $18,23,24$ inc. $2^{\circ}$ y 25 ; b) las que establecen sanciones civiles, a las que pertenece la triple opción de la LPC de los arts. 19 y 20 y C) algunas de carácter mixto. CORRAL (1999), pp. 169-170.

${ }^{6}$ Barrientos (2011), p. 359.

${ }^{7}$ Término que ha sido criticado, pues confundiría los efectos propios de la resolución con la institución que regula. En ese sentido véase PeÑaILlillo (2003), pp. 395 y 431. Véase también, Barrientos (2016), p. 200. 
fiere optar por la resolución, para buscar otras alternativas volviendo a acudir al mercado a adquirir el bien fabricado en masa ${ }^{8}$. Así, el bloqueo o vulneración del reembolso obliga a la mantención de una relación entre consumidor y proveedor que el primero no desea, cuestión que podría sostenerse como una práctica abusiva ${ }^{9}$. Lo anterior al menos estaría en contradicción con el carácter obligatorio de la garantía legal, en el sentido de ser un derecho irrenunciable ${ }^{10}$ por el consumidor, establecido como tal en la $\mathrm{LPC}^{11}$.

\section{Problematización}

El presente trabajo tiene por finalidad la observación de las circunstancias y características que el reembolso, en cuanto garantía legal, presenta en la fase extrajudicial, pues estudios realizados por el Sernac, muestran un panorama de poca eficiencia de la regulación, evidenciado en que una gran cantidad de las reclamaciones realizadas surgen a raíz de la imposibilidad para ejercer la garantía legal, y dentro de ella el reembolso.

Los datos aportan que es en la venta al detalle (retail) donde este problema cobra mayor relevancia. El año 2018 el total de reclamaciones ante el Sernac fue de 330000 , siendo el 33\% de estas en el ámbito del retail ${ }^{12}$. En años anteriores, por ejemplo, el año 2016 el Sernac recibió 27803 reclamos relacionados con la garantía legal, siendo un 32,58\% de estos motivados por la no devolución del dinero producto del reembolso. Para diciembre de 2017 el Sernac había recibido 23007 reclamos relacionados con problemas para ejercer el derecho a la garantía legal, y de ellos, un $38,56 \%$ por no devolver el dinero ${ }^{13}$.

A lo largo de la investigación, se sostiene que, en las relaciones de consumo, junto con la garantía legal, están operando otros remedios tutelares o, bien, se realizan prácticas que la vulneran o resultan abusivas, y serían

\footnotetext{
${ }^{8}$ Barrientos (2014), p. 72. Reiterado en Barrientos (2016), p. 210.

${ }^{9}$ Esto entendiendo la naturaleza de los contratos de comercio en general como contratos de adhesión. Véase BARAona (2014), p. 389 y ss.

${ }^{10}$ Cabe apreciar la mirada contraria y crítica de la naturaleza del derecho de opción, que ha planteado que la irrenunciabilidad debe, al menos, ser matizada, a fin de desenmascarar el sistema remedial como puramente garantista. Lo relevante es que abandonar el carácter de obligación de esto podría excluir su tutela remedial. FERrANTE (2018c), pp. 190-193.

${ }^{11}$ Fuentes (2012), p. 17.

${ }^{12}$ Información disponible en www.sernac.cl/portal/604/articles-55432_archivo_01. pdf [fecha de consulta: 11 de abril de 2018].

${ }^{13}$ Según datos de www.sernac.cl/regalo-viejito-pascuero-presenta-fallas-consumidoresderecho-garantia-legal-navidad/ [fecha de consulta: 27 de julio de 2018].
} 
estos remedios y prácticas las que dificultan, por parte del vendedor, la elección y ejecución del reembolso.

Estos remedios tienen características muy diversas ${ }^{14} \mathrm{y}$, en ocasiones, no están regulados de forma expresa ${ }^{15}$. Generalmente se agrupan bajo la denominación de garantías convencionales o voluntarias ${ }^{16}$.

El Sernac reconoce entre ellas a la garantía de satisfacción ${ }^{17}$ y la garantía extendida ${ }^{18}$, a pesar de que corresponden a estándares comerciales o pólizas de seguros, y que en muchas ocasiones confundan a los consumidores en el ejercicio de sus derechos ${ }^{19}$. Lo relevante será que estas garantías, muchas veces pueden encontrarse vigentes junto con la garantía legal, de tal manera que, al concurrir con ella se hace necesario determinar su coordinación ${ }^{20}$.

En ese sentido el art. 21 inc. 9 de la LPC, que obliga al consumidor a agotar las posibilidades que le son ofrecidas por este tipo de garantías antes de proceder a ejercer la garantía legal21. Así esta se configura como

${ }^{14}$ Algunas de estas se encuentran la distinción entre “a) garantías del fabricante y b) las garantías convencionales o extendidas” por BARRIEnTOS (2016), p. 360 y ss. Por otra 126 parte, la distinción entre “a) La garantía que compromete el mismo vendedor o prestador del servicio al consumidor o usuario; b) Una garantía que viene otorgada por el fabricante, importador o distribuidor, y que es conferida al consumidor por intermedio del vendedor directo; c) Una garantía llamada extendida, que ofrece el vendedor previo pago de una suma adicional por parte del consumidor”. CORRAL (2011a), pp. 411-412.

${ }^{15}$ Marinakis (2015), pp. 54-55.

${ }^{16}$ Entendidas como "aquellas ofrecidas voluntariamente a consumidores por los productores de los bienes durables, o por los vendedores de estos, y que se refieren al amparo sobre cualquier defecto que se manifieste en un plazo determinado". SERNAC (2012), p. 10. Además, en Fuentes (2012), p. 12.

${ }^{17}$ Se entiende como "un ofrecimiento adicional ofertado por el proveedor, generalmente una multitienda, y que cubre la posibilidad de cambio o devolución de lo pagado por el producto, incluso en casos no contemplados para la garantía legal”. SERNAC (2012), p. 12.

18 "Aquella que cubre un periodo de tiempo por sobre la garantía convencional o voluntaria y una vez que esta ha expirado. Este tipo de mecanismo es de costo del consumidor y corresponde a una póliza de seguro". SERnAC (2012), p. 12. Además, en Fuentes (2012), p. 13.

${ }^{19}$ Sernac (2012), pp. 8-9.

${ }^{20}$ Barrientos (2016), p. 236.

${ }^{21}$ Esta es una primera postura con base en el tenor literal de la disposición, según la cual la garantía legal solo podría hacerse valer cuando se agoten las herramientas que la garantía voluntaria otorga, explica en atención a la tesis defendida por la denunciada, en la causa Briones Moreno con Automotores Gildemeister S.A., según la cual no corresponde la acción indemnizatoria, si esta no se considera en la garantía voluntaria. ISLER (2014), p. 584 . 
"una garantía mínima, obligatoria y de alcance general, por lo cual, si el proveedor ha ofrecido una garantía por mayor plazo o de más amplio espectro de cobertura, prevalecerán los términos de esta”22.

En contraposición a lo anterior, aquellos que consideran que el derecho de opción tiene un carácter público ${ }^{23}$, y que, por tanto,

"no podría ocurrir que las garantías convencionales o del fabricante restringieran los derechos reconocidos en la ley, que son irrenunciables anticipadamente para el consumidor. Dicho de otro modo, las garantías voluntarias o las garantías del fabricante no podrían limitar ni restringir los remedios de la garantía legal" ${ }^{24}$.

Se sostiene que, al operar del modo descrito por la primera postura, se vulnera la garantía legal en general, y en particular se bloquea la posibilidad de optar por el reembolso.

\section{Objetivo general o principal}

Ante lo descrito, y bajo la hipótesis de que en las relaciones de consumo la existencia de otros remedios, garantías o prácticas empresariales podría estar afectando la facultad de requerir el reembolso por parte del consumidor, es que el trabajo busca identificar circunstancias y características que el reembolso, en cuanto garantía legal, presenta en la fase extrajudicial en tiendas de retail.

\section{Objetivos especificos}

A partir del desarrollo del objetivo general será posible, además, reunir información de otras temáticas, que permiten establecer los siguientes objetivos específicos.

a) Constatar el cumplimiento de las normas establecidas en la Ley n. ${ }^{\circ} 19496$.

b) Identificar diferentes formas en que el reembolso se incorpora en la fase extrajudicial de las tiendas de retail.

c) Verificar la concurrencia de otros remedios o prácticas en conjunto con la garantía legal.

${ }^{22}$ Fernández (1998), p. 119.

${ }^{23}$ En ese sentido Barrientos (2016), p. 236.

${ }^{24}$ Barrientos (2011), p. 361. 
d) Dar cuenta de la posible interferencia entre dichos remedios o prácticas con la ejecución del reembolso.

\section{El MÉTODO}

Para ello se realiza una revisión del tratamiento del reembolso en el marco de la garantía legal, por instituciones que se dediquen a la venta del retail, que según el Sernac abarca:

"farmacias, tiendas por departamento, tiendas de mejoramiento del hogar, supermercados (hipermercados, supermercados, tiendas de conveniencia y tiendas de descuento) y tiendas especialistas" 25 .

Bajo esta definición, el estudio se enfocó en centros comerciales, pues es en ellos donde el retail tiene su mayor expresión al ser posible encontrar los diversos tipos de tiendas de retail. Así fueron tres los centros comerciales en los que se aplicó la entrevista: Mall Plaza Vespucio, Mall Florida Center y Costanera Center, debido a su ubicación en las comunas con mayor flujo de visitas a centros comerciales ${ }^{26}$.

La participación de cada tienda debía ser voluntaria y por tal motivo se elaboraron distintos documentos, entre ellos, una carta de presentación, un consentimiento informado y un cuestionario base de la entrevista ${ }^{27}$, los que fueron entregados desde un principio presencialmente en las tiendas, a fin de informar los objetivos e implicancias de la participación para los entrevistados y obtener su colaboración.

Cuarenta $^{28}$ tiendas/empresas accedieron a participar sometiéndose a la entrevista, entre ellas dos supermercados y dos grandes tiendas, diversas tiendas especializadas ya sea de ropa, tiendas de accesorios deportivos, tiendas de calzado y librerías ${ }^{29}$. En cada tienda se realizó una entrevista, consultando al encargado o jefe de tienda, o a la persona que él designó, en atención a sus conocimientos acerca de cómo operan las garantías en su empresa, y en específico cómo se configura la práctica del reembolso.

${ }^{25}$ Sernac (2017), p. 10.

${ }^{26}$ De acuerdo con un estudio realizado por la empresa de geointeligencia GEORESEARCH (2014), los centros comerciales que cuentan con mayor flujo de visitas son Plaza Vespucio y Costanera Center.

${ }^{27}$ Véanse en anexos n. ${ }^{\circ} 1 \mathrm{y} \mathrm{n} .^{\circ} 2$.

${ }^{28}$ En concreto, cuarenta tiendas accedieron a participar y otras diecinueve tiendas y supermercados rechazaron la invitación, argumentando mayormente políticas internas.

${ }^{29} \mathrm{La}$ individualización se omite, pero se encuentran disponible, habiendo las tiendas otorgado el consentimiento a someterse a la entrevista gestionada. Véase anexo n. ${ }^{\circ} 3$. 
De ese modo, los sujetos entrevistados fueron jefes de tienda, vendedores en sala y encargados de atención al cliente.

El instrumento de recolección de información se compuso de treinta y siete preguntas que abordaron temáticas de garantías en general, pero con especial énfasis con el reembolso. Las entrevistas fueron realizadas en los meses de junio y julio de 2018, y la información obtenida fue transcrita, ordenada y categorizada a fin de presentarla de una manera clara.

\section{ANÁLISIS DE INFORMACIÓN}

Con el objetivo de realizar un análisis dinámico se agrupó la información obtenida en una serie de categorías que servirán de guía en la lectura de los datos. La intención es que estas permitan una comprensión sistemática de la práctica del reembolso, en virtud del modelo establecido en el art. 20 "a falta de conformidad en las faltas de especificaciones, la calidad de las cosas y la vinculación publicitaria" 30 .

\section{Derecho a la información y especificaciones legales}

Mencionado de forma expresa en la LPC en su art. $3^{\circ}$ letra b), se manifiesta en la entrega de información oportuna sobre los bienes y servicios ofrecidos, el precio, condiciones de contratación y otras características relevantes de los mismos, y como contraparte el deber de informarse responsablemente de ellos ${ }^{31}$.

Cualquier contravención o falta en la información especificada en la ley, configurará una falta de especificación legal o convencional según sea el caso ${ }^{32}$.

${ }^{30}$ Barrientos (2016), p. 170. Donde se explica que en dichas circunstancias tiene lugar la garantía legal.

${ }^{31}$ La guía de alcances jurídicos elaborada por Sernac señala: "los proveedores no deben incurrir en imprecisiones que generen confusión en los consumidores a partir de información parcial o incompleta, como por ejemplo, 'cambios sólo los diez primeros días', cuando lo que en realidad lo que se quiere decir es que la empresa posee una política comercial de satisfacción a todo evento, pero que ello no excluye bajo ningún circunstancia, los derechos de opción que tienen los consumidores los tres primeros meses de recepción de un bien nuevo, de acuerdo a la garantía legal”. SERnaC (2012), p. 4.

${ }^{32}$ Francisca Barrientos incorpora esta sistematización en el marco del análisis de la conformación del incumplimiento en la entrega conforme. En su monografía la autora sintetiza la configuración del incumplimiento en relación con tres faltas de conformidad estas son: A. Faltas de conformidad y anomalías de cantidad; B. Faltas de conformidad y falta de especificaciones y C. Falta de conformidad y anomalías de Calidad. Para más información, véase BARRIENTOS (2016), pp. 137-168. 


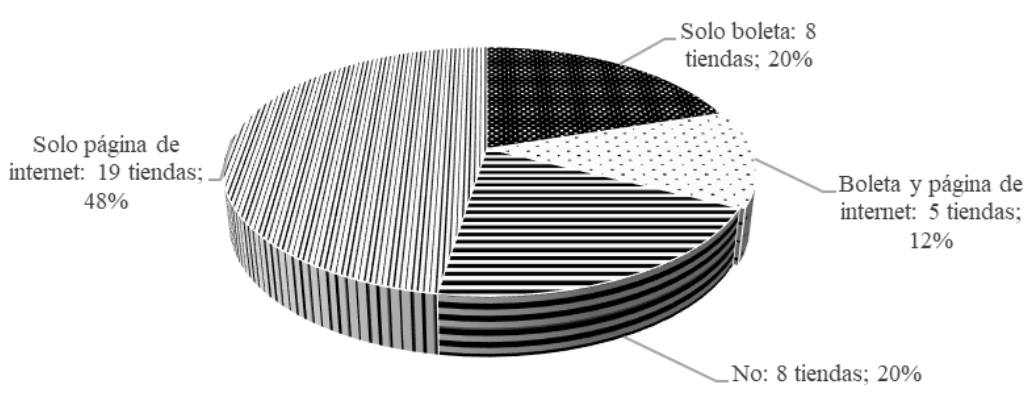

Los datos obtenidos dan cuenta de que las tiendas suelen desplegar sus políticas de cambios y devoluciones de manera visible en el local al momento de la venta o por medio de plataformas virtuales. En ellas se establecen los supuestos en que es posible pedir el reembolso, los plazos para ejercerlo, condiciones en que debe encontrarse el bien que se devuelve, etcétera.

Ahora bien, de lo observado en las boletas e informativos exhibidos en las tiendas, en al menos veinte de ellas se advierte que las garantías son presentadas bajo la denominación "garantías de cambio". Por su parte, la información relativa al reembolso se encuentra relegada a espacios mínimos 130 dentro del documento ${ }^{33}$. Además, es posible encontrar slogans como "Elige fácil, elige cambio", un detalle que manifiesta ya en lo formal un posicionamiento tendencioso que busca incentivar la elección por el cambio del producto en desmedro de la reparación o el reembolso.

Ocho tiendas no expresan la información respecto de las garantías físicamente al momento de la compra, y tampoco señalan los medios para obtenerla, cuestión que vulnera el derecho a la información, señalado en la ley, y que en nada resguarda la posición del consumidor al momento de la compra.

Las empresas que realizan ventas mediante internet entregan dicha información al momento de realizar las compras en sus plataformas, y afirman la existencia de protocolos distintos para esas compras, por ejemplo, con la incorporación del retracto en las ventas realizadas mediante internet.

\section{Convivencia de la garantía legal y otras garantías}

En ocasiones concurren, junto con la garantía legal, garantías extendidas o de satisfacción ${ }^{34}$.

${ }^{33}$ Es decir, todo lo relativo a las devoluciones de dinero aparece con letras pequeñas en comparación con las grandes afirmaciones referidas a la opción "cambio" y su regulación.

${ }^{34}$ Doctrinariamente se ha entendido la concurrencia de garantías, bajo la denominación: compatibilidad externa. En su monografía Francisca Barrientos analiza en forma 
A partir de esto se asienta el debate doctrinal agrupado en dos posiciones $^{35}$ :

La primera en torno al tenor literal del art. 21 inc. $9^{\circ}$ de la LPC, que obliga a agotar las posibilidades ofrecidas por las garantías del proveedor antes de poder ejercer los derechos otorgados por el art. 20, en definitiva, antes del reembolso ${ }^{36}$. De ahí que existan fallos que consideran legítima la práctica del proveedor que, en virtud de una garantía convencional, se reserva el derecho de reemplazar el producto defectuoso por uno de semejante funcionalidad ${ }^{37}$.

Por otra parte, una segunda posición sostiene que, a pesar de existir una garantía convencional, el consumidor puede optar por ejercer las opciones que presenta la garantía legal, dado su carácter de derecho irrenunciable ${ }^{38}$. Solo así se configuraría un entendimiento armónico del art. 21 de la LPC, y en caso de ser más gravosa la garantía convencional debe primar la garantía legal ${ }^{39}$.

La jurisprudencia de la Corte Suprema apoya esta segunda postura, en fallos que otorgan al consumidor la posibilidad de ejercer la garantía legal sin agotar antes las garantías convencionales existentes ${ }^{40}$.

La adopción de una u otra postura resulta central a la hora de establecer el alcance de la protección de la LPC por medio de la garantía legal $\mathrm{y}$, aunque se argumenta por medio de consideraciones jurisprudenciales, esa definición puede incidir en cómo se configura la fase extrajudicial del reembolso, ya que la norma actual es interpretada por los proveedores ${ }^{41}$ como un impedimento a la libre elección al concurrir una garantía conven-

detallada las compatibilidades con garantías del fabricante, la garantía del vendedor, y la compatibilidad con servicios de posventa. BARRIEntos (2016), pp. 241-252.

${ }^{35}$ Véase Marinakis (2015), p. 69 y ss.

${ }^{36}$ En este sentido Francisco Fernández señala como requisito para ejercer la garantía legal el "haber agotado previamente las opciones que ofrezca la póliza de garantía cuando se trate de productos vendidos con garantía voluntaria”. FERnández (2003), p. 38. En el mismo sentido trabajos iniciales de Hernán Corral en los que señalaba "la triple alternativa no se abre si hay una garantía ofrecida por el proveedor”. CORRAL (2006), p. 118. Opinión modificada entendiendo que para la eficacia práctica de la ley se requiere de una "primacía de la garantía legal por sobre la voluntaria, y no viceversa". CORRAL (2011a), p. 421.

${ }^{37}$ Irarrázaval con Antofagasta Store Co. S.A. (2008), en la que se acoge la postura de la parte demandada en el sentido de ser suficiente la garantía otorgada por la tienda, que ofrecía el cambio del producto por uno nuevo de similar característica. Mismo criterio expuesto en Scheihing con París (2010).

${ }^{38}$ Barrientos (2016), p. 236.

${ }^{39}$ Marinakis (2015), p. 77.

${ }^{40}$ Scheihing con París (2011).

${ }^{41}$ Entiéndase aquí por proveedores a vendedores, importadores y fabricantes, en conformidad al inciso segundo del art. 21 de la LPC. 
cional y la garantía legal ${ }^{42}$, y por medio de esa interpretación justifican las limitaciones de la garantía legal e, incluso, la prohibición del reembolso.

Los resultados obtenidos de la aplicación del instrumento de recolección de información permiten graficar la convivencia de la garantía legal con otras instituciones, de la siguiente forma:

Opciones de garantías que presenta la tienda. (f.2)

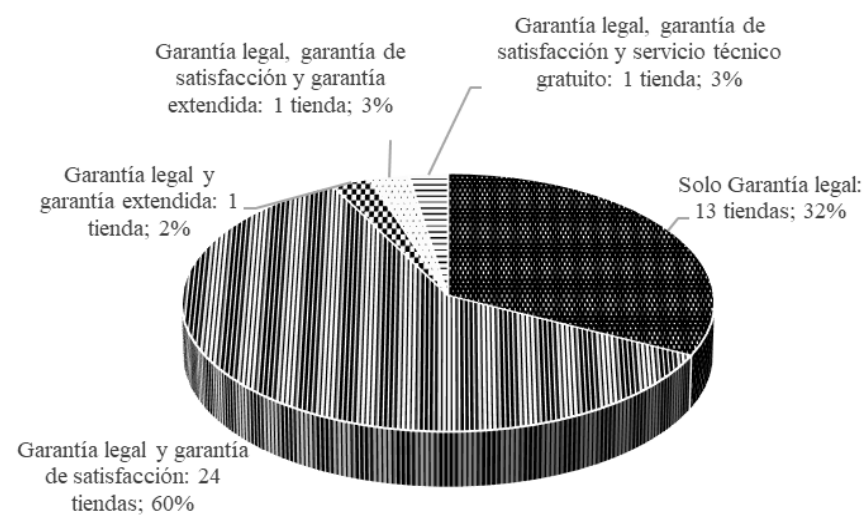

Principalmente la garantía legal se ve acompañada por garantías que 132 las tiendas señalan como de satisfacción, esto es así en veinticuatro de ellas. En dos ocasiones, además, se añaden otras opciones como el servicio técnico y una garantía extendida.

Las garantías de satisfacción identificadas incluyen por lo general el cambio o devolución de dinero sin requerir la inaptitud del bien para el fin al que está destinado, remedio al que denominan retracto. Lo característico de estas opciones son periodos cortos, que en caso de cambio alcanza solo los treinta días, y de reembolso como máximo los diez días.

Acerca de la interacción entre remedios, se preguntó por la existencia de un orden en que estos han de ser pedidos. En quince ocasiones el ejercicio de la garantía legal, en específico de la devolución de dinero por falla, queda bloqueada, ya que el cliente tiene obligaciones previas, ya sea de concurrir a la reparación del producto o pasar por la revisión del servicio técnico, para que aquel determine el remedio aplicable.

En tres tiendas se afirma que "sólo procede la devolución de dinero por defectos de fabricación y hasta un plazo máximo de diez días desde realizada la compra". Cuestión contraria a la legislación vigente sobre la garantía legal.

${ }^{42}$ Wilkins (2019), p. 6. 


\section{Existe algún orden de efectuar las reclamaciones.}

\section{(f.3)}

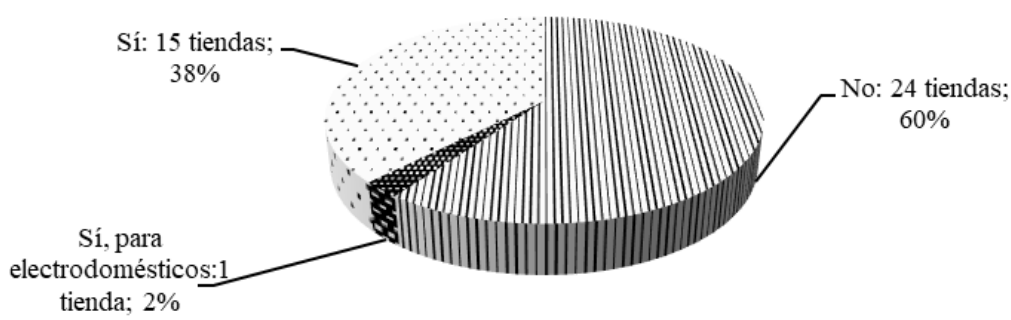

Aquellas tiendas sostienen que esto es así, pues mediante sus propias garantías entregan una cobertura más amplia que la garantía legal, y el menor plazo para la realización de reembolso se compensaría con el hecho de que este se podrá pedir ante todo evento, sin limitaciones en lo relacionado a la calificación del motivo. Además, luego de los diez o siete días para retractarse, el cliente podría optar por un cambio, lo cual sería suficiente para satisfacer las necesidades de los consumidores.

La situación descrita resulta patológica ${ }^{43}$, y la jurisprudencia ha apoyado dicha valoración, expresándose que

"hacer primar a todo evento la garantía convencional por sobre la legal, importaría autorizar al proveedor para que por la vía del establecimiento de regímenes convencionales -incluso a título gratuito- pudiera limitar el ejercicio de los derechos que la ley confiere" ${ }^{4}$.

En cuanto a las variaciones en las garantías que puedan incorporarse con motivos de fechas especiales como Navidad o día de la madre, que son justamente los periodos que conllevan más peticiones de garantías (y más reclamos en el Sernac), no se corroboran mayores cambios, aunque sí un grupo de doce tiendas manifiestan extender la posibilidad de realizar

${ }^{43}$ La doctrina ha identificado que cláusulas por adhesión de este tipo "anterior o posterior a la celebración del contrato, impuesta por aquel vendedor que quiso hacer contratar al comprador la garantía convencional, en desmedro de la legal", resulta patológica y contraria a los principios de buena fe y configura una práctica irregular y sancionable. FERRANTE (2018c), p. 191.

${ }^{44}$ Briones Moreno con Automotores Gildemeister S.A. (2013). En ella se señala con relación a la problemática de concurrencia de garantías que "las disposiciones de los arts. 20 y 21 de la LPC, autorizan al consumidor, en situaciones como la que sirve de fundamento al presente proceso, para requerir, entre otras posibilidades, a su elección, al vendedor, la devolución de la cantidad pagada (cons. octavo)". 
cambios en términos ajenos a las fallas de los productos, ya no solo por treinta días, sino que se llega a los sesenta o noventa días.

\section{¿Cambia el protocolo en fechas de alta demanda?}

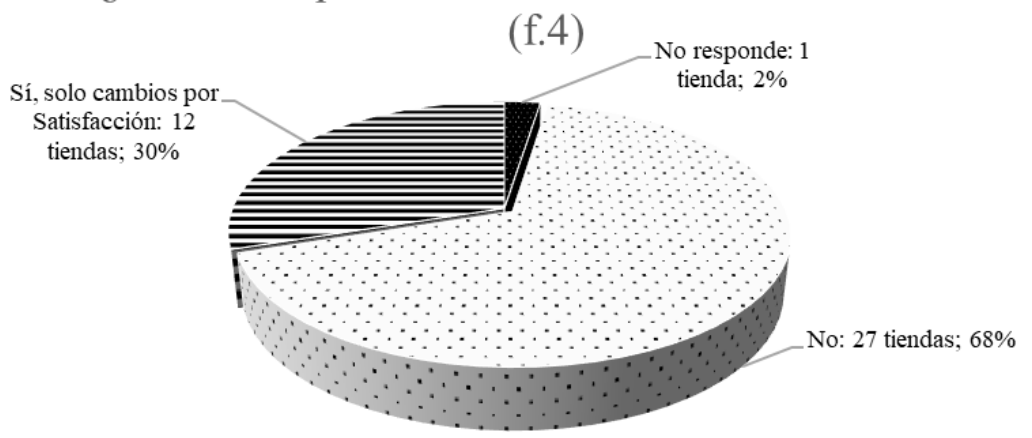

\section{Compatibilidad interna}

De la lectura de la LPC la elección del reembolso, el cambio o la reparación no está sometida a jerarquías de ningún tipo ${ }^{45}$. Es decir, la posibilidad del consumidor de optar sin condiciones por el remedio que más le convenga, es en sí mismo un derecho ${ }^{46}$ que no puede ser limitado en forma alguna por el proveedor ${ }^{47}$. Sin embargo, se ha constatado que, a pesar de esta supuesta opción, en determinados casos existiría una verdadera jerarquía, sobre todo en las ventas a distancia ${ }^{48}$.

Aun así, la tendencia jurisprudencial ha impuesto como doctrina mayoritaria una suerte de primacía de la reparación en sede judicial en lo que se ha denominado, jerarquía legal de la reparación ${ }^{49}$.

${ }^{45}$ Barrientos (2016), p. 222.

${ }^{46}$ Fuentes (2012), p. 17.

${ }^{47}$ Franzani con Giuseppe Ltda. (2008). En dicho fallo se señala que cada alternativa de la garantía legal "es privativa del consumidor, sin que el proveedor pueda exigir el cumplimiento de una determinada de ellas"; Vera con Forus S.A. (2010). En la que se señala que en la práctica ante la elección por parte del consumidor de uno de los remedios posibles en la garantía legal, que al caso en concreto correspondia la cambio del producto, el proveedor no puede negarse. Muñoz con Óptica Máster (2008). En ese sentido véase Walker con supermercado de muebles y colchones Speisky y Compañía Ltda. (2007); Roth con Sociedad Rip Chile S.A. (2010); Sernac con Todo Piel S.A. (2011).

${ }^{48}$ Esta problemática ha sido analizada recientemente por FERRANTE (2019b), pp. 893921. En dicho artículo se identifican tres modelos remediales en virtud del momento en que se emite la boleta y se realiza la entrega del bien, cuestión que, en definitiva, configura el momento en que comienza a regir el plazo para solicitar alguna de las opciones que la garantía legal concede, y que, por tanto, resulta distinta en ventas presenciales y no presenciales.

${ }^{49}$ Francisca Barrientos se hace cargo de esta situación explicando que la tendencia judicial mayoritaria ha impuesto una especie de jerarquía pretoriana o judicial de la 
Recientemente en una sentencia de la Corte Suprema ${ }^{50}$, se encuentra una relevante consideración en relación con la libre elección de los derechos contenidos en el art. 20 de la LPC y la prescripción ${ }^{51}$. Cuestión que pudiera traducirse en el futuro en la aplicación de este criterio por la jurisprudencia nacional.

\section{Opciones dentro de la garantía legal. (f.5)}

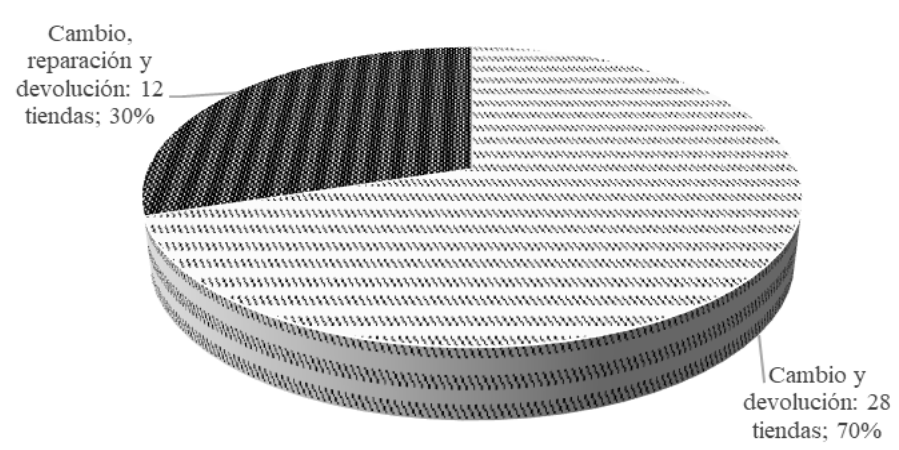

Todas las tiendas manifiestan la existencia de la triple opción y además que la facultad de exigir el cambio, la reparación o devolución, es exclusiva del cliente.

Aun así, de los resultados se desprende una primera restricción a la garantía legal, ya que solo doce tiendas presentan la posibilidad real de efectuar la reparación de un producto, siendo lo común la posibilidad de efectuar cambios y devoluciones. Los entrevistados señalan que en atención a la naturaleza de los bienes que ofrecen, la elección de la reparación sería inverosímil y contraproducente, pues resultaría ser una operación más cara y engorrosa. La reparación solo es ofrecida en tiendas que ofrecen productos de alta gama, como zapatos de alto valor y trajes de vestir, o aquellas que venden electrodomésticos y máquinas de ejercicios.

Entonces, ya sea que se verifiquen las tres opciones, o que solo sea posible optar por el cambio y el reembolso, casi la totalidad de los sujetos entrevistados dan cuenta de la preferencia por la realización de cambios. Las razones esgrimidas son: en primer lugar, la dificultad de ejercer una devolución versus la facilidad que otorga el cambio, de tal forma los entrevistados declaran que: "el trámite es más sencillo para ambos (cliente y tienda)", o

reparación, que explica en función de dos situaciones. Por un lado, la confusión entre la denuncia de la anomalía y la elección del remedio de reparación y, por otro, la interpretación del art. 20 letra e). BARRIENTOS (2016), pp. 225-232.

${ }^{50}$ Sernac con La Polar S.A. (2017). En ella se reconoce como infracción la negativa del vendedor a otorgar los remedios requeridos por el comprador de una lavadora defectuosa, en el caso se pedía la sustitución del bien o la devolución de dinero, ofreciendo solo la reparación.

${ }^{51}$ Ferrante (2018b), p. 248. 
"primero le ofrecemos la opción de cambiarlo. Porque es lo más fácil de hacer, y luego si no hay otra cosa que le guste esta la opción de devolverle el dinero".

Esta justificación en principio razonable en términos de conveniencia para ambos actores, en realidad traspasa una dificultad propia del sistema de la tienda al cliente, siendo que el consumidor no tiene incidencia en las dificultades técnicas que pueda implicar la operación. Es más, no es posible olvidar que es un deber del vendedor, a la hora de la reclamación de garantía legal, propiciar condiciones similares, esto es, no más gravosas que las existentes al momento de la compra ${ }^{52}$.

Una segunda justificación se elabora en atención con la variedad de productos que la tienda ofrecería, ya que con ellos se superaría la necesidad de realizar reembolsos por medio del cambio por otro producto de la tienda. En ese sentido y ante la pregunta respecto de un orden de prelación entre las opciones de la garantía legal:

"No un orden, pero si se muestran otros productos al cliente pues existe gran variedad al tener cuatro marcas en las que puede elegir un producto".

Esta práctica de someter la procedencia del reembolso a la condición de que no exista otro producto de similares características en la tienda agrega un requisito ajeno a lo establecido en la ley, entendiendo que ante la disconformidad material del bien de consumo ya nace la opción, que es solo del consumidor, de optar por una de las opciones que entrega la garantía legal.

En tercer lugar, los entrevistados manifiestan que el sustento de las justificaciones emana de las instrucciones dadas por la empresa: "al cliente se le va a ofrecer el cambio, aunque él pida la devolución, pero es una cuestión propia de la estrategia de venta", incluso se declara que:

"no es rentable estar llenándose de notas de crédito, así que a ti te entrenan un poquito para no llenarte de notas de crédito y que ésas sean más bien cambios".

Esto último no puede tener justificación dentro de la lógica del derecho de consumo, que justamente busca resguardar la desigual posición en que se encuentra el consumidor y el vendedor, toda vez que lo que se hace es traspasar la responsabilidad del costo operacional del reembolso.

${ }^{52}$ Así lo expresa el art. 21 de la LPC, en su inc. $6^{\circ}$. 
Una justificación en tal sentido atenta contra la esencia de la legislación de consumo, y no debe ser aceptada.

En al menos tres de las tiendas la orden es no realizar notas de crédito, salvo casos muy específicos, esto es, cuando el cliente ya se muestra enfadado y reticente a las demás opciones. $\mathrm{Al}$ respecto entrevistados señalan:

"ya si uno se da cuenta que la persona esta ofuscada entonces ahí uno, para evitar problemas, hace la devolución y después avisa al supervisor, porque hay gente que se enoja demasiado".

Este es uno de los escenarios más extremos que se han identificado, ya que salvaguardando los intereses de la tienda se somete al consumidor a situaciones de estrés injustificados, cuestión que no solo lo vulnera en sus derechos de consumo, sino que en cierto sentido podría afectar su dignidad, al propiciar condiciones de incomodidad degradantes, y que, en ocasiones, dan como resultado situaciones de agresividad. En ese sentido una asistente señaló que no se hacían devoluciones de dinero, salvo

"cuando es mucho el problema, por ejemplo, cuando nos insultan, porque viene mucha gente agresiva, llamamos a la supervisora y hacemos la devolución. Un hombre me tiró la bolsa en la cara a mí porque quería el dinero. Mucho insulto y ropa sucia”.

Resulta interesante la dinámica que se da en tiendas que venden ropa interior, puesto que una de las entrevistadas sostiene que ellas no tendrían la obligación de aceptar devoluciones de ropa por cuestiones de higiene, y que si ellos lo realizan es por "mera cuestión de servicio". Esto no se condice con lo dispuesto por el Sernac, que no considera este supuesto como eximente de responsabilidad ${ }^{53}$.

Las prácticas de relegar la devolución o posponerla a una última instancia, someten al consumidor a un régimen abusivo, pues, aunque no exista agresividad o tensión se ve forzado a pasar por una serie de etapas, como la atención del cajero, la revisión del encargado, la autorización de la devolución, además del discurso acerca de la facilidad de realizar un cambio por sobre la devolución, cuestión que tiene como objetivo desincentivar al cliente en su decisión.

53 "El que una tienda advierta que no se admite devolución para la ropa interior aludiendo razones de higiene, no la exime de responder a la garantía que establece la ley si el producto tiene fallas de calidad". Por tanto, que el consumidor tenga la opción de requerir la reparación del producto, el cambio o la devolución de lo pagado por reembolso. Información disponible en diversas plataformas del Sernac, entre otras www.sernac.cl/194204/ y www. sernac.cl/165704/ [fechas de consulta: 11 de abril de 2018 y 15 de junio de 2018]. 
Todo parece originarse en la manera en que las tiendas se disponen ante la devolución del dinero. En gran parte de las entrevistas la devolución que conlleva el reembolso es valorada como una cuestión perjudicial, ya que se entiende como una pérdida. Se menciona, por ejemplo, que por medio de ella la tienda pierde una venta, pierde el monto que significa la operación, pierde tiempo en la atención del cliente, en la realización de las notas de crédito y en la posterior realización de cuadraturas. Desde esa visión elaboran sus estrategias y políticas comerciales, y que se ve reflejada en las infografías y las normativas particulares.

Solo seis tiendas entrevistadas, sostienen abiertamente un discurso distinto, no enfocado en lo perjudicial del reembolso, sino en la satisfacción del cliente. En esa línea se señala que "la estrategia de venta del local es la que se enfoca hacia la mantención del cliente, y una buena atención” o

"todo se relaciona a la idea de mantención del cliente en cuanto estos, por ejemplo, han comprado durante treinta años y no puedes perderlos por no cambiarle o devolverle lo pagado por una sábana".

\section{Tipo de responsabilidad y calificación del incumplimiento}

Si bien la LPC no señala si la responsabilidad a que da lugar la garantía legal es de carácter subjetiva u objetiva ${ }^{54}$, en la jurisprudencia se ha recogido la objetividad $^{55}$, ya que permite establecer que el proveedor deba reparar todo el daño causado sufrido ${ }^{56}$.

${ }^{54}$ IsLer (2014), p. 579. Cuestión que tiene relevancia en concreto, pues "importaría la eventual condena o absolución del proveedor”. En ese sentido también BARROS (2008a), p. 309. La opción por una u otra de las responsabilidades favorecerá al proveedor o al consumidor, puesto que la subjetiva importa una responsabilidad por culpa, es decir, solo será responsable de los daños ocasionados aquel sujeto a quien pudiera atribuírsele la falta de cuidado o diligencia. En cambio, la responsabilidad objetiva permite establecer que el proveedor debe reparar todo el daño causado sufrido, pudiendo alegarse como causas de exoneración solo las señaladas en la ley de forma expresa.

${ }^{55}$ Por parte de la doctrina se ha señalado: "el hecho de que el comprador deba responder incluso ante defectos de fábrica demuestra que la garantía legal [...] prescinde de la evaluación de la conducta del vendedor, por lo que no se trata de una obligación civil, sino de una responsabilidad tendencialmente objetiva”. Ferrante (2018b), p. 247. Véase también, Briones Moreno con Automotores Gildemeister S.A. (2013). No obstante, fallos que han considerado lo contrario, véase Sernac con Almacenes París Comercial S.A. (2006). Aunque finalmente se falló en relación con una cuestión más concreta, ya que la controversia se definió en torno a si esta se hizo valer o no dentro del plazo establecido.

${ }^{56}$ Ya que solo en las obligaciones de medios se exige una conducta diligente al deudor para que logre la satisfacción de la prestación comprometida. PizArRo (2008), pp. 257-258. 
Luego, al momento de optar por la devolución de dinero, se produce una nueva discusión en torno a si procede o no la calificación del incumplimiento para determinar la aplicación de uno u otro remedio ${ }^{57}$. Discusión que es superada ${ }^{58}$ considerando que tal calificación no rompería la horizontalidad de las opciones, debido a que es natural que cada remedio en particular presente sus propios límites y requisitos ${ }^{59}$.

En lo que respecta al reembolso, la calificación se justifica en la medida que implica la resolución del contrato por parte del consumidor, esto es, la opción por un quiebre del vínculo contractual que dejará sin efecto lo pactado $^{60}$. De ahí se plantea la idea de que, para la procedencia de la resolución, el incumplimiento deba clasificarse como resolutorio o esencial ${ }^{61}$.

El producto que da lugar al reembolso será aquel que no es idóneo, es decir, no cumple con el fin que se propone, pues no reúne las cualidades sobre las cuales recayó el consentimiento contractual o adolece de un vicio $^{62}$, y aún más,

"no sólo las fallas del producto que hacen imposible su uso natural, sino también aquellas que tuvieron lugar antes o durante la compra, como las propiedades señaladas por el anunciante, la apariencia o presentación del producto y los términos y condiciones establecidos en el contrato" ${ }^{63}$.

Esta parece una forma armónica de entender la calificación del incumplimiento, toda vez que el espíritu de la ley es precisamente la pro-

${ }^{57}$ Sobre todo, porque la LPC no menciona tal calificación, como tampoco la legislación que regula las ventas en el $C C$. Barrientos (2016), pp. 201-202.

${ }^{58}$ La única excepción que ha sostenido la no calificación del incumplimiento en la resolución de los contratos se ha dado en materia civil, no acerca de la legislación de consumo, y se atribuye a Arturo Alessandri, como señala la misma autora, op. cit., p. 203.

${ }^{59}$ Ibid. Siguiendo a FenOY (2006), p. 69.

${ }^{60}$ PeÑallillo (2003), p. 431. “...el consumidor no quiere seguir vinculado con el proveedor y prefiere optar por la resolución para buscar otras alternativas para adquirir el bien fabricado en masa". BARRIENTOS (2014), p. 72. La misma autora agrega que el hecho de calificar el incumplimiento no importa una limitación a la libre opción del consumidor, sino, más bien, es una medida de equilibrio de las relaciones contractuales. BARRIENTOS (2016), p. 202.

${ }^{61}$ VIDAL (2009), pp. 221-258. Poniendo énfasis en la legislación de consumo, los insumos para la calificación se extraen de que "el precio pagado por el consumidor en una compra de un bien durable, le concede el derecho a que por ese dinero pagado se le entregue un bien de la calidad adecuada, apto para cumplir el propósito natural al cual se destine ese bien, y sin que se produzca una desvalorización de su inversión”. SERNAC (2012), p. 2.

${ }^{62}$ Corral (1999), p. 166. Independiente si esto es así por deterioro, adulteración o imperfección.

${ }^{63}$ Manque (2006), pp. 72-73. 
tección del consumidor en la relación de consumo debido a su posición desmejorada. Siendo así, la protección no debe agotarse a determinados instantes dentro de la relación contractual, sino que debe extenderse a cualquier situación que vulnere sus derechos.

\section{Supuestos del reembolso. (f.6)}

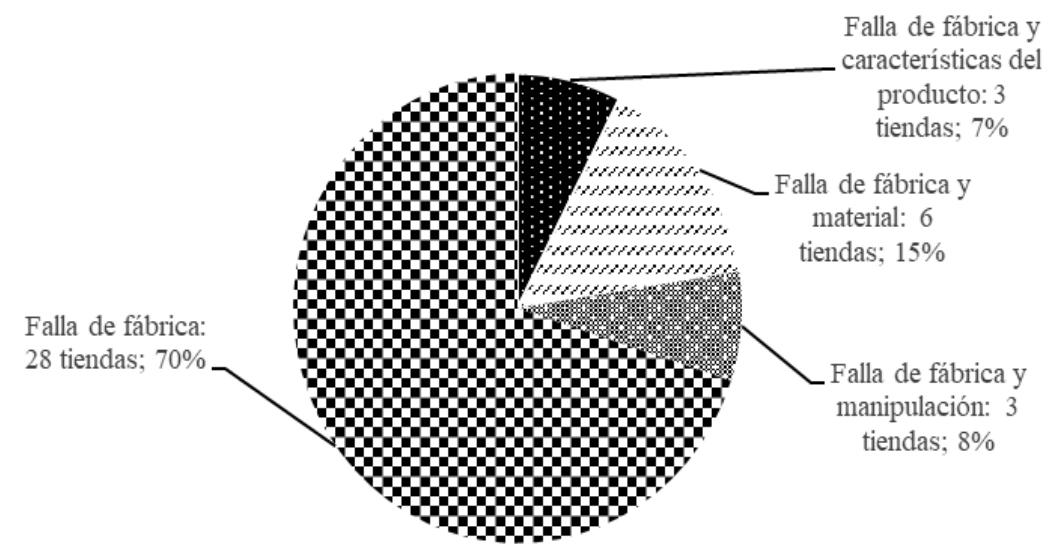

Los datos obtenidos dan testimonio de que, en la fase extrajudicial 140 del reembolso, todas las tiendas llevan a cabo una calificación de las circunstancias que conforman el incumplimiento.

Esta calificación, se basa en la idea de la no idoneidad del bien para la realización del uso al que está destinado. Pero en desmedro de la protección amplia señalada, los datos obtenidos dan cuenta de que la mayoría de las tiendas realizan una reducción de los alcances de la idoneidad a lo que denominan falla de fábrica. Con ello las posibilidades de solicitar el reembolso se ven limitadas, y los supuestos de hecho son los menos.

Por falla de fábrica, las tiendas entienden aquella que se presenta en el producto en su proceso de creación o fabricación, y no considera situaciones que se dan en la conformación de la relación contractual, ni posteriores a la venta. Dependiendo de los productos que cada tienda ofrece, se manifiesta de diferentes formas: las librerías entrevistadas consideran en ella los productos mal compaginados, mal impresos o con pá_ginas en blanco; en tiendas dedicadas a la venta de ropa se considera las costuras descosidas, fatiga de material, accesorios despegados, error en estampados, falla en los cierres; en tiendas dedicadas a la venta de zapatos o zapatillas se incluyen despegue de plantas, rebanamiento de plantas, mal funcionamiento de sistemas de aire en calzados especializados.

Únicamente al concurrir este tipo de fallas es posible acceder a la garantía legal, quedando fuera la falta de idoneidad derivada, por ejemplo, de la falta de información o falsedad de la información otorgada al 
momento de la compra, falta de especificaciones de uso, falta de algún elemento del producto por la manipulación de este.

Seis tiendas, agregan el supuesto falla de material, que no tendría que ver con el proceso de elaboración del producto, sino que se relaciona con las características propias de la mercadería. En ella se entienden incorporados casos de descoloramiento de productos textiles, accesorios despegados o falta de algún accesorio del producto.

Tan solo tres tiendas incluyen la posibilidad de devolución por "error de manipulación", que viene a ser el error que se comete en el momento de la compra por parte del vendedor, por ejemplo, al entregar dos zapatillas de distinta talla o del mismo pie, o la entrega de un producto distinto al comprado.

Un reducido grupo de tres tiendas, en particular aquellas que venden productos de alta gama o con tecnologías especializadas, como artefactos de alta montaña o de outdoor, añaden el error en las características, esto es, que las prendas no resistan las especificaciones ofrecidas en las etiquetas de los productos y también aquellas que fueron ofrecidas por el vendedor al momento de la compra, por ejemplo, si se aseguró la impermeabilidad o la resistencia al frío, y la prenda no cumplió dichas características.

En suma, son pocas las tiendas entrevistadas que se hacen cargo de la visión amplia de la garantía legal, es decir, que permiten optar por el reembolso fuera de las situaciones generadas en la fabricación del producto. Así, la denominación falla de fabrica no hace más que limitar la posibilidad efectiva de solicitar el reembolso por parte de las tiendas.

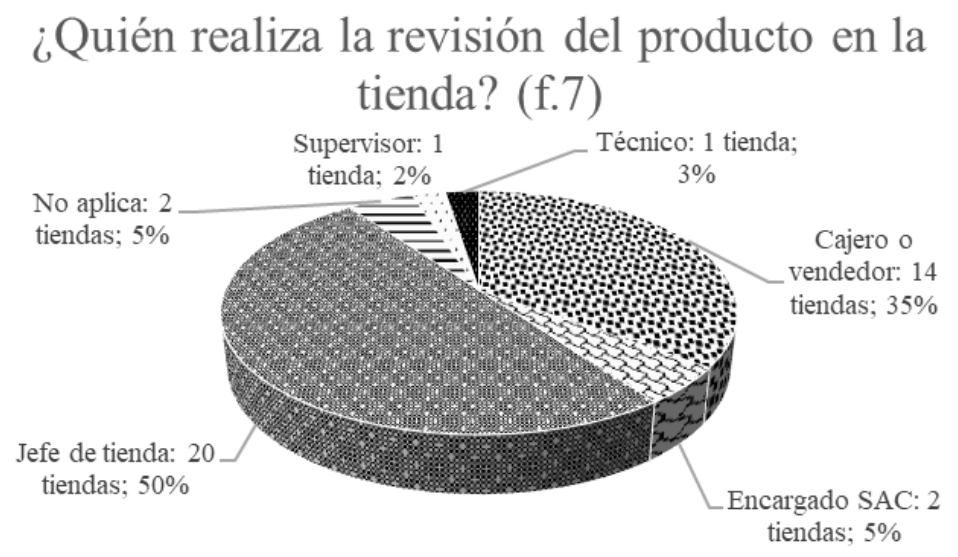

Respecto del protocolo de la revisión, el 85\% de las tiendas realiza una revisión primaria del producto en el mismo local, ya sea por jefes de tienda, cajeros o vendedores. Pero en todas ellas debe, además, ser autorizado por el encargado, jefe o subjefe de la tienda. Si bien el hecho de que la revisión se realice en la tienda agiliza el proceso, toda la celeridad 
se diluye cuando el encargado que debe otorgar la autorización no está disponible en el local, que suele ser de común ocurrencia.

Además, la revisión en tienda solo es definitiva en el caso de una falla evidente, fácilmente apreciable. En cambio, cuando la falla corresponde a cuestiones técnicas y no distinguibles a simple vista, se debe someter el producto a la evaluación del servicio técnico, por lo general, exterior al local.

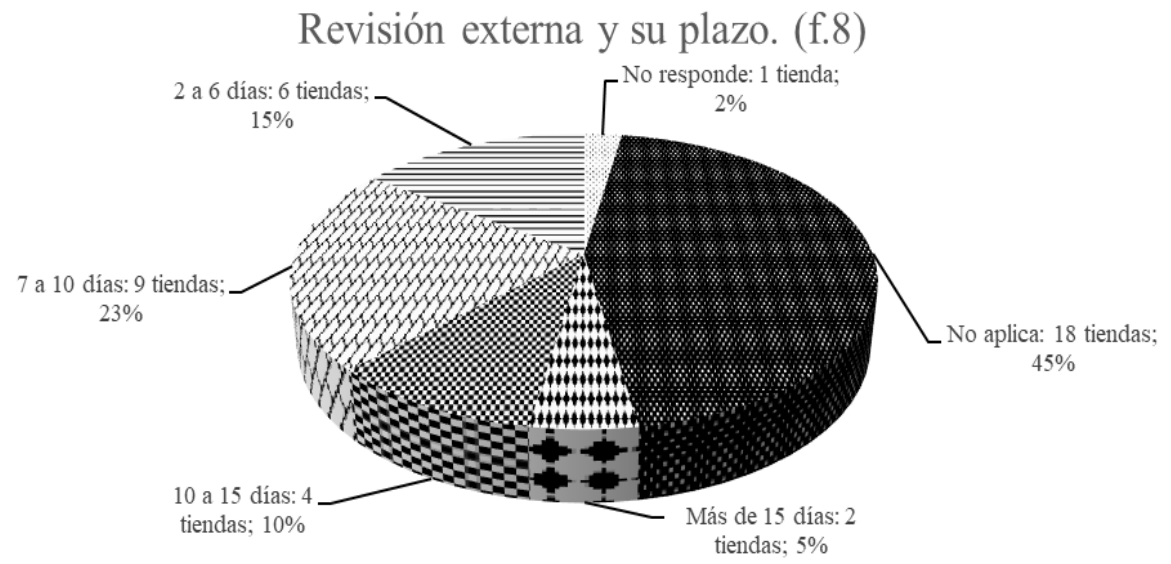

142 En el segundo escenario lo normal es que en el local se efectúe una ficha de ingreso, y que junto con ella se envíe el producto a la revisión externa. Teniendo la tienda el deber de informar cuando la revisión concluya.

Los plazos de revisión fluctúan entre los dos a los veintiún días hábiles, dependiendo tanto de la distancia al lugar de revisión como del tamaño del producto, cuestiones que se informan en los protocolos internos. Los bienes con mayor plazo de revisión fueron los de productos electrodomésticos, y aquellos comprados en regiones cuya revisión se efectúa en Santiago.

La existencia de este intervalo de tiempo en que transcurrirá la revisión no contraviene la normativa de consumo, pero sí es discutible la razonabilidad de la duración de dicha revisión, ya que en ocasiones transcurrirán semanas sin que el consumidor pueda obtener su dinero para volver a concurrir al mercado a obtener el bien de consumo, cuestión que tiene una influencia directa en su decisión, y que, por lo tanto, no debiera ser establecida arbitrariamente por el vendedor.

Lo que sí contraviene la normativa de consumo en forma directa es lo observado en cuatro de las tiendas, en las cuales los productos son enviados a revisión un día determinado de la semana. Por tanto, si un cliente llega el día siguiente a aquel, deberá esperar la semana siguiente para que el producto sea recién enviado a la revisión. Esto dificulta el proceso y, en ocasiones, también ocurre con relación a los cambios. En ese sentido declaraciones como: "aquí los cambios sólo se hacen los jueves y viernes". 
Esta práctica es contraria a la legislación en materia de consumo, y es entendida así por el Sernac ${ }^{64}$.

\section{Formas de ejecución}

a) Ejercicio extrajudicial de esta acción

En virtud del art. 1489 del $C C$, la resolución del contrato producirá sus efectos una vez declarada ejecutoria la sentencia, dictada en juicio ordinario. En cambio, el reembolso en la relación de consumo, opera como un derecho potestativo del consumidor, que solo necesitará su declaración de voluntad para poner término a la relación ${ }^{65}$.

Como contraparte este tiene el deber de acreditar el acto o contrato que ha dado origen a la relación. Así lo requieren todas las tiendas, ya sea en ejercicio de garantía legal, como para acreditar cualquier otra garantía, ya sea de satisfacción o extendida.

\section{Instrumento para pedir garantías. (f.9)}

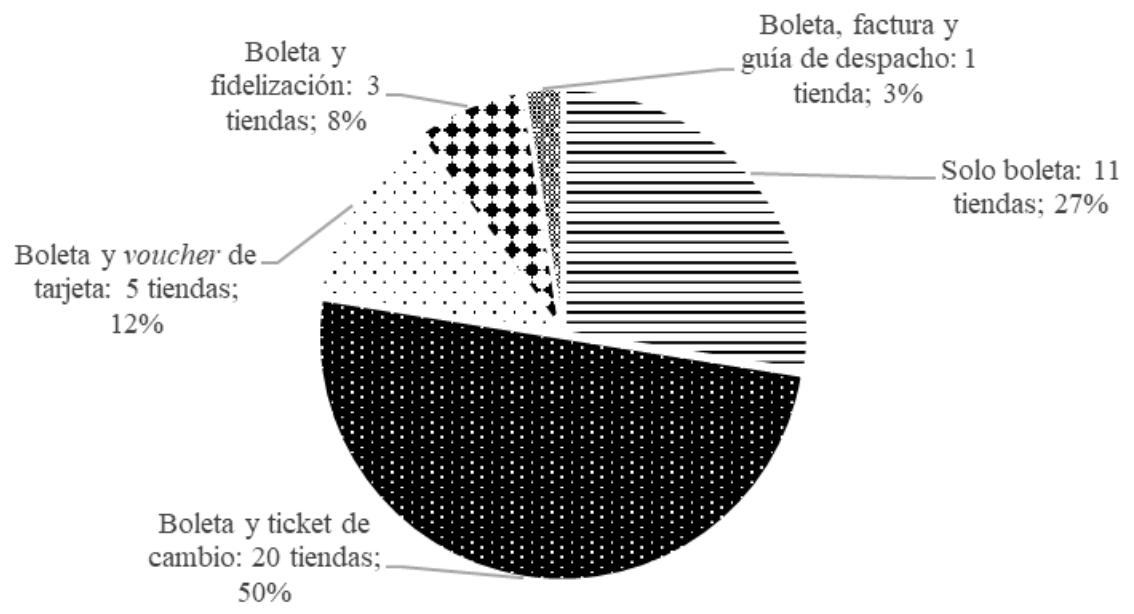

Como se aprecia en la f. 9, la documentación exigida para hacer valer las distintas garantías es en general, y principalmente la boleta, y luego el ticket de cambio.

${ }^{64}$ SERnAC (2012), p. 10. "El hecho de condicionar el ejercicio del derecho de opción a través de prácticas comerciales como son la fijación de días u horarios, para proceder al cambio o devolución de dinero, son contrarios a lo establecido en la LPC".

${ }^{65}$ Se ha afirmado que esto es así, en el entendido de que la ley no ha dispuesto una defensa judicial al caso, a diferencia de lo sucedido con la garantía por servicios, por ejemplo, en que de forma expresa se exige la determinación por un juez. BARRIENTOS (2016), p. 209. 


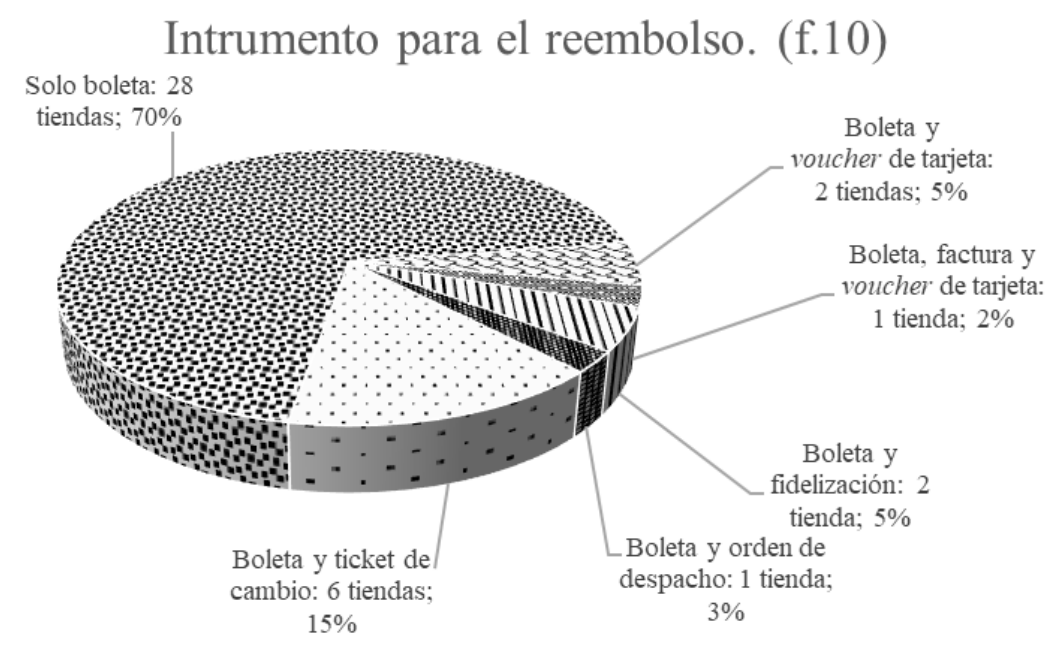

En lo referido a garantías en general, veinte tiendas cuentan con el documento ticket de cambio, pero estas mismas tiendas señalan que en cuanto al reembolso el ticket no reemplaza a la boleta, solo seis tiendas permiten solicitarlo por medio del ticket de cambio.

En casos aislados, las tiendas cuentan con otros medios para pedir la devolución, como la fidelización del cliente, es decir, la realización y revisión de un archivo de la compra junto con los datos de cada cliente. Otra opción surge en caso de que la compra fuere efectuada mediante tarjeta de crédito, en cuyo caso, es posible hacer la petición presentando el voucher que se genera al momento de la compra.

La importancia de que se exija la boleta original por parte de la tienda radica en la delimitación de quien se pretenda sea el sujeto activo, ya que, en un primer acercamiento, la experiencia común da cuenta de que la boleta suele quedar en manos de quien ha realizado la compra, a diferencia el ticket que queda en manos del sujeto que recibe el producto para su uso.

Desde la doctrina se distingue entre el legitimado activo de la garantía legal y el consumidor, sobre todo en cuanto a la dificultad de la definición de este último ${ }^{66}$. Para ello resulta útil la distinción entre consumidor jurídico, quien adquiere el bien o servicio, y el consumidor material, que es, en definitiva, el sujeto que lo utiliza o disfruta ${ }^{67}$.

${ }^{66}$ Para una revisión pormenorizada de la complejidad de la definición de consumidor en el ordenamiento chileno es pertinente el análisis expuesto respecto del contratante a tiempo compartido. Por lo pronto, se valora lo expuesto respecto de que la definición inicialmente positiva de consumidor, como destinatario final del bien, debe ser complementada, pues ahora incorpora patrones negativos, pasando a ser una definición híbrida. Ferrante (2018a), p. 448.

${ }^{67}$ Barrientos (2011), p. 363. 
Una parte de la doctrina ha entendido que el reembolso puede ser alegado por quien adquiere, esto es, quien se hace dueño de un producto por medio de la compraventa, resultando excluido quien lo disfruta ${ }^{68}$. Con ello, la exigencia de la boleta original y la concurrencia de otra documentación, como el documento de identidad correspondiente, resultan justificados $\mathrm{y}$, en ocasiones, necesarios.

\section{Persona habilitada para pedir devolución.} (f.11)

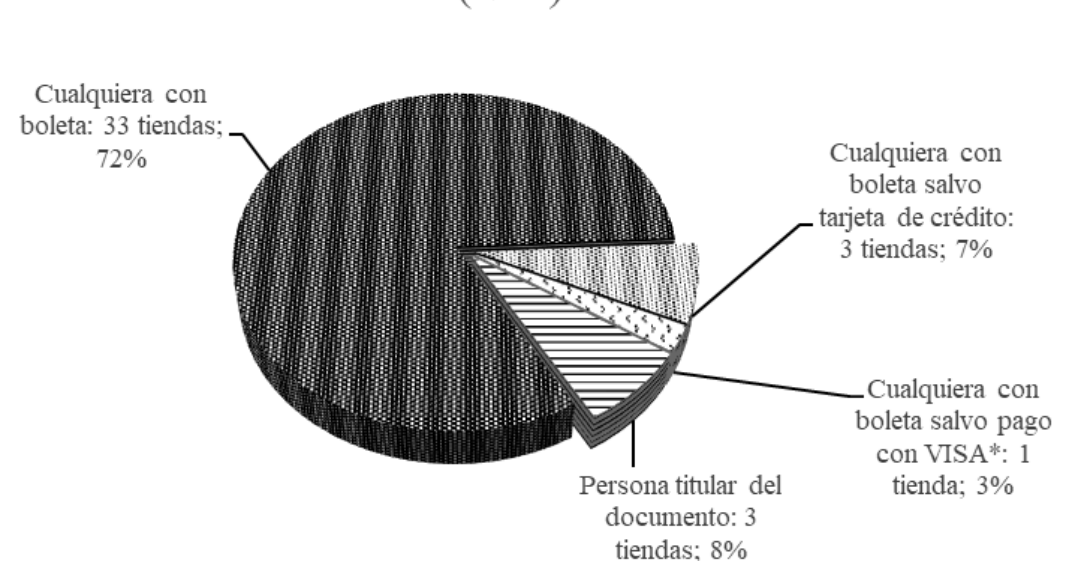

Por otra parte, se considera que existen variadas razones para incorporar a los consumidores materiales dentro de la protección efectuada por la $\mathrm{LPC}^{69}$, con ello sería posible requerir el reembolso por medios distintos a la boleta.

Treinta y siete de las empresas manifiestan que no solo el sujeto que adquirió el bien puede hacer la reclamación, sino que, también, un tercero no presente en el momento de la compra. Eso sí, siempre que presente la boleta de la compra.

Situación distinta en caso de pago mediante tarjeta de crédito, en la que sí se requiere que al menos esté presente el comprador. Según las palabras de los entrevistados, esto es así debido al carácter personal de la tarjeta a la que se realizará la operación de reversa. Más extrema es la posición de tres tiendas que exigen, independiente del medio de pago,

${ }^{68}$ En ese sentido Hernán Corral ha señalado: "parece claro que la ley sólo otorga derecho al consumidor adquiriente del bien, es decir, a quien ha celebrado el contrato con el vendedor", refiriéndose al derecho de opción consagrado en la garantía legal. Corral (2011b), p. 110.

${ }^{69}$ En tal sentido se ha expresado que "de la definición de consumidor resulta evidente que se ha incluido tanto al que se ha denominado consumidor jurídico -quien adquierecomo al consumidor material-quien utiliza o disfruta". JARA (1999), p. 61. 
que quien realice la reclamación de reembolso sea el mismo sujeto que compró el producto.

En este punto se valora que por medio de la boleta sea posible que el consumidor material acceda a la garantía legal, pues al menos en ese sentido se amplía el campo acción de dicha garantía.

\section{Lugar en que se hacen las reclamaciones. (f.12)}

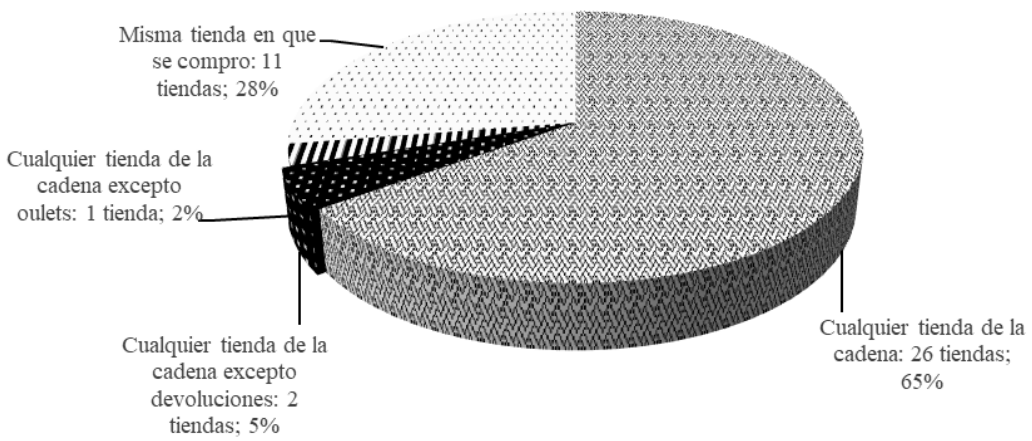

En cuanto al lugar en que deben hacerse las peticiones de garantía legal, en general las respuestas apuntan a la misma tienda, o en cualquier 146 otro local perteneciente a la cadena.

En concreto once tiendas ${ }^{70}$ exigen que las peticiones sean en el mismo local donde se compró el producto, arguyendo, por ejemplo, razones de inventario.

La revisión de los resultados permite apreciar que la práctica de situar las peticiones de garantía en el mismo lugar en que se compró el bien va en sintonía con los requerido por la ley en el art. 21 de la LPC ${ }^{71}$.

b) La gratuidad de las restituciones

Ya sea que se opte por el cambio, la reparación o el reembolso, el carácter gratuito de las restituciones resulta un elemento de la esencia ${ }^{72}$ de la garantía

${ }^{70}$ Una de las tiendas declara que, aun cuando la reclamación de la garantía puede hacerse en cualquier tienda de la cadena, las devoluciones sí deben ser requeridas en la misma tienda en que el producto se compró.

${ }^{71}$ Dicho artículo señala: "el vendedor, fabricante o importador, en su caso, deben responder de los derechos que surgen de la garantía legal en el mismo local donde se efectuó la venta o en las oficinas o locales en que habitualmente atiende a sus clientes, no pudiendo condicionar el ejercicio de dichos derechos a efectuarse en condiciones menos cómodas para el consumidor que las que se le ofreció para efectuar la venta, salvo que éste consienta en ello". SERnAC (2012), p. 10.

${ }^{72}$ Esta resulta del carácter gratuito de las prestaciones. Además, se añade que las restituciones deben ser completas, esto es, sin retención de gastos. BARrientos (2016), p. 208. 
legal. Respecto del último, esto se traduce en que no se puede cobrar al cliente por los gastos operacionales que implique la devolución del dinero, como tampoco es posible realizar descuentos en el valor devuelto ${ }^{73}$.

Todas las tiendas manifiestan que, de acceder al reembolso, el monto entregado no sufre variaciones en relación con el valor que el producto tenía al momento de la compra ${ }^{74}$.

Las respuestas de las tiendas se presentan casi uniformes, en que la devolución se lleva a cabo en dinero, y no en otros productos u opciones. Sólo cinco tiendas la efectúan por otros medios distintos de la devolución en dinero.

\section{Forma de devolución en efectivo y débito.}

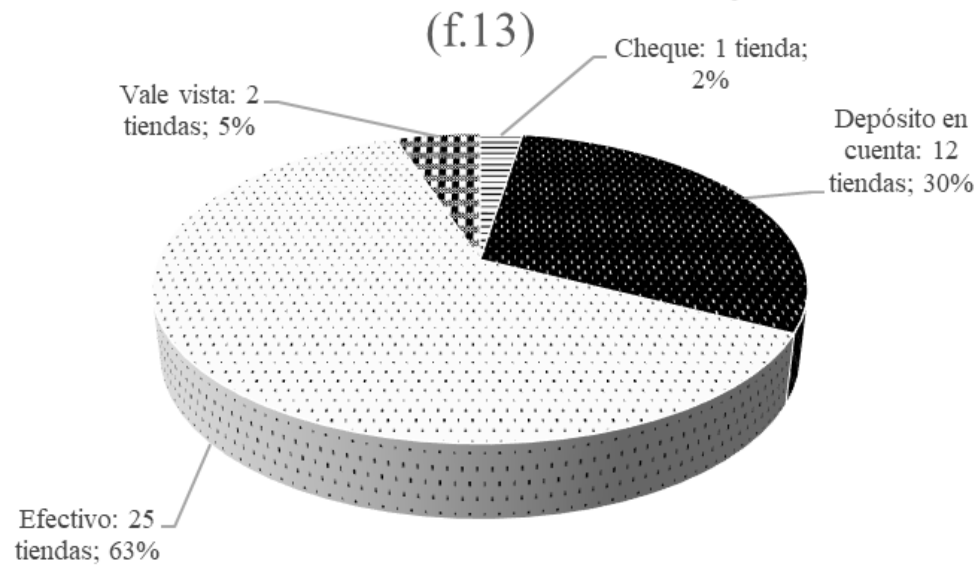

Entre las últimas se identificó la entrega de bonificaciones o tarjetas como las denominadas giftcards; o la existencia, en una empresa, de una opción denominada store credit, que es una tarjeta con un saldo para utilizar, en el plazo de un año, en la cadena de la tienda ${ }^{75}$. Estas modalidades, al igual que el forzamiento por el cambio, impiden recibir la devolución efectiva de su dinero, que es lo que busca el consumidor al optar por el

${ }^{73}$ La única excepción al pago total del importe se da una vez transcurridos los tres meses, situación en la cual solo podrá obtener el precio neto del bien excluyéndose los impuestos correspondientes. En virtud de lo estipulado en el art. 70 del DL n. ${ }^{\circ} 825$.

${ }^{74}$ Esta afirmación por parte de las tiendas es valorable, pues la utilización del bien durante la fase judicial de la solicitud "puede ser tenido como una medida para compensar el daño y mitigarlo; si así fuera, no debería reducirse la devolución de la cantidad pagada, pero sí interpretarse de manera más restrictiva el importe a conceder en la eventual solicitud -acumulativa- de daños y perjuicios, allí donde se den sus presupuestos”. FERRANTE (2019a), pp. 767-768.

${ }^{75}$ Cabe la precisión de que dicha opción que es obligatoria en la devolución por concepto de garantía de satisfacción, y opcional cuando lo que se está reclamando es el reembolso en términos de garantía legal. 
reembolso, y sobre todo impiden el efecto resolutivo que se le ha atribuido a este último, manteniendo unilateralmente la relación contractual.

En general, cuando el medio de pago de la compra es efectivo o débito, las devoluciones son realizadas en efectivo o depósito en cuenta. Salvo en contadas ocasiones en que se hace entrega de un cheque o un vale vista, los cuales de todos modos importan la devolución íntegra del dinero pagado al momento de la compra.

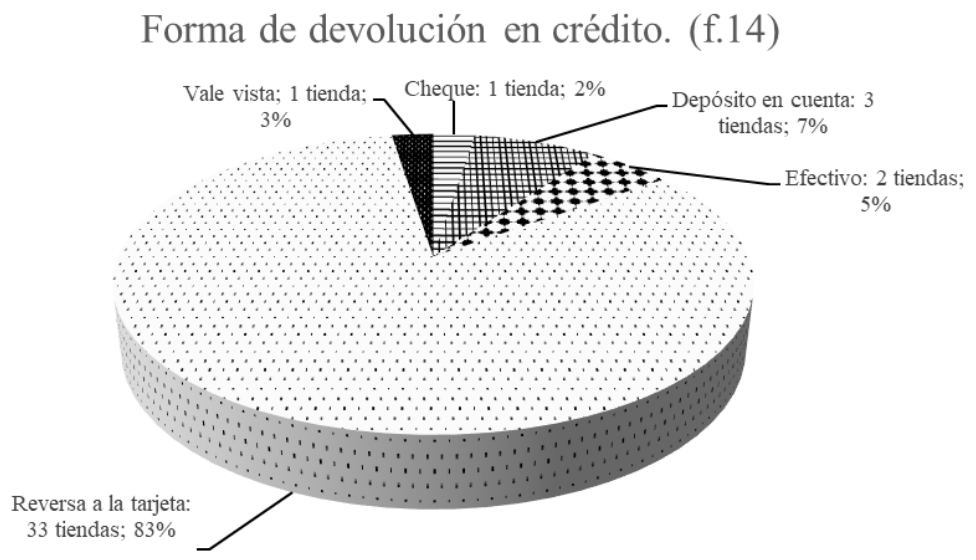

Distinto es cuando se paga por medio de tarjetas de crédito, pues en tal caso el reembolso se realiza a través de una reversa en el sistema Transbank $^{76}$, lo que añadirá a la operación un nuevo tiempo de espera, ahora dependiente de un sujeto externo al vendedor, y claro está, al consumidor. Este periodo de espera funciona como un desincentivo a optar por el reembolso en las compras mediante tarjeta de crédito.

Ante la pregunta por la incidencia de la variación del valor del producto considerando los momentos de compra y petición, se obtuvo que, de haber variación, no altera el cálculo del monto de la devolución. Con ello, se sigue el principio de restitución integral, que se valora en doctrina, y que es consagrado en la indemnidad patrimonial ${ }^{77}$. Pero en todo caso el monto de lo devuelto se agota en la devolución nominal de la cifra pagada, sin producirse reajustes a dicho monto $^{78}$.

${ }^{76}$ Sistema de pago y soluciones en operaciones mediante tarjetas electrónicas. TRANSBANK (2018).

${ }_{77}$ Criterio extraído de los arts. 3 letra e) y 27 de la LPC, que la establecen como un principio que informa las normas de protección de los consumidores. Valorado por el Sernac a fin de "liberar oportunamente al consumidor de toda carga, con la finalidad de proteger la facultad de disposición de los bienes de su propiedad”. SERnaC (2019), p. 9.

${ }^{78}$ Pese a ello existe jurisprudencia que valora la posibilidad de incluir reajustabilidad en la devolución del dinero producto del reembolso, según la cual este "no puede alcanzar 
Interesante es lo aportado en dos tiendas que realizan el servicio de despacho de los productos. En esas entrevistas se advierte que el despacho es un elemento externo al valor del producto y, por tanto, la devolución de dinero que deviene del reembolso no incorpora el valor de dicho transporte.

\section{c) Forma de devolución de los productos}

Una cuestión constante en las tiendas es la exigencia de la devolución del producto para poder solicitar el reembolso, pese a que dicha exigencia pudiera ser discutida ${ }^{79}$.

Con motivo de establecer el modo en que el bien debe ser devuelto para que opere, se destaca que el producto es uno, aun cuando esté conformado por diversas piezas ${ }^{80}$. La relevancia de lo mencionado radica en que, debido a la especialización de las fuentes de producción y los procesos de fabricación, los bienes finales de consumo masivo son manufacturados por partes o piezas ${ }^{81}$, y en ocasiones, el incumplimiento se configura por la no idoneidad de una parte del producto.

Por otra parte, la tendencia observada en los resultados indica que las tiendas no suelen requerir las etiquetas exteriores o bolsas en caso de la ropa, ni el embalaje en caso de artículos electrodomésticos, tampoco la caja de los zapatos o zapatillas es requerida cuando se pide la devolución de dinero. Tan solo tres tiendas exigen el embalaje original al momento de la devolución por falla. Parece correcto que así sea, pues dicho requisito no tiene justificación en la normativa acerca de la garantía legal, sino que, de intentarse, derivaría de una aplicación por analogía del art. $3^{\circ}$ bis letra b) de la LPC, que en particular regula el retracto en los medios electrónicos, por tanto, no necesariamente obligatorio para el reembolso.

Diez de las tiendas ponen énfasis en la importancia de las etiquetas interiores en la ropa, debido a que de esta forma es posible identificar la prenda como parte del stock de la tienda y, además, en ella se expresan las condiciones de cuidado, lavado y planchado de las prendas, suministros útiles en la revisión del bien, pues ellas incorporan los deberes del con-

solamente a la suma numérica del precio pagado, sino a esta debidamente reajustada de acuerdo con la depreciación monetaria”. Como se expresó en Mella con Dunn F. y Dunn y García Ltda. (2006).

${ }^{79}$ Como se mención la devolución previa del bien para solicitar el reembolso no es una cuestión del todo pacifica y las soluciones jurisprudenciales no son unívocas, existiendo la posibilidad de que en la fase judicial se solicite el importe de lo pagado sin la restitución previa del bien, lo que en algunos casos permitirá la utilización del bien mientras dure el contencioso. Ferrante (2019a), pp. 761-763.

${ }^{80}$ Así lo señala expresamente la norma en el inciso final del art. 20 de la LPC.

${ }^{81}$ Barrientos (2013), p. 538. 
sumidor, y si el producto ha fallado por no respetarse estas indicaciones, la tienda rechazará la petición.

d) Plazo

El plazo para ejercer las acciones de la garantía en el ámbito del consumo está fijado por el art. 21 de la LPC, que señala el dies a quo, en los siguientes términos:

"Tratándose de la devolución de la cantidad pagada, el plazo para ejercer la acción se contará desde la fecha de la correspondiente factura o boleta y no se suspenderá en caso alguno" ${ }^{2}$.

Muchas de las tiendas cuentan con otras instituciones remediales $\mathrm{u}$ otras garantías, y aquellas presentan plazos que van desde los diez a los treinta días desde la compra.

Con motivo de la garantía legal las respuestas son armónicas en torno a que es exigible desde el mismo día de realizada la compra hasta los noventa días, por tanto, lo mismo ocurre con el reembolso.

En dos de las tiendas, si la solicitud es realizada el mismo día de la compra, la devolución procede automáticamente vía efectivo, indepen150 diente del modo de pago. En cambio, la modalidad varía según sean otros los medios de pago, sobre todo cuando se ha realizado una operación mediante tarjeta de crédito ${ }^{83}$.

Tres tiendas señalan que el plazo único para solicitar el reembolso es de diez días desde la fecha de la compra, esto ofrece durante ese periodo una garantía de satisfacción a todo evento como única posibilidad de obtener la devolución de dinero. Transcurrido ese lapso, el cliente solo tendrá la opción de cambiar el producto o la reparación de este.

Lo descrito, es una práctica que vulnera el plazo legal establecido para la petición de la garantía legal y de aceptarse este tipo de indicaciones por parte de las tiendas se generan espacios de desprotección hacia el consumidor, pues se le quita la posibilidad solicitar el reembolso, cercenando el derecho de garantía legal.

${ }^{82}$ Cabe la salvedad en el caso de los productos perecibles o que por su naturaleza estén destinados a ser usados o consumirse en plazos breves, en este caso es de siete días. BARRIENTOS (2013), p. 532. Además, la precisión aportada por Alfredo Ferrante respecto del esfuerzo por parte de los tribunales de interpretar esta norma en virtud de una "protección efectiva del comprador, prescindiendo de una lectura ortodoxa que, de imposibilitar la suspensión del plazo, alteraría sus máximas de resguardo”. FERrante (2019b), p. 896 y ss.

${ }^{83}$ Como se ha dado cuenta supra. f. 14 . 
e) Protocolos de reembolso

El art. 21 de la LPC es la principal clave para leer los datos obtenidos mediante la aplicación del cuestionario. En él se expresan: el sujeto pasivo de la acción, que en el caso particular del reembolso será únicamente el vendedor $^{84}$, el plazo en que deberá ejercitarse esta acción; la circunstancia de responder el vendedor en el ejercicio de los derechos en el mismo local donde se efectuó la venta u oficinas u otros locales y la imposibilidad de relegar el procedimiento a condiciones menos cómodas que las existentes al momento de la compra.

De las respuestas obtenidas lo primero que resulta claro es que cada tienda articula de forma propia el protocolo para pedir el reembolso, como también las operaciones de devolución de dinero que este conlleva, estableciendo distintos plazos, días para efectuar las operaciones, modos de enterar las devoluciones, lugares de reclamación, formas de revisión del producto, etcétera.

Sí aparece como un hecho común la generación de una nota de crédito ${ }^{85}$ cada vez que se requiere el reembolso, pues mediante este instrumento las empresas y tiendas realizan la reversa de la compra, que luego permite la devolución del dinero pagado por el cliente. Eso sí, existen particularidades respecto de si la nota de crédito es otorgada en la misma caja de la tienda, como se corrobora en veinticuatro ocasiones, o si la nota es gestionada en oficinas distintas a la caja del local, incluso en oficinas externas a la tienda como se obtuvo en dieciséis entrevistas. Esto afecta al cliente, pues según sea la modalidad implicará un menor o mayor tiempo de operación.

La devolución del dinero producto de la nota de crédito varía en relación con la forma de pago. Tanto el efectivo como el débito tienen igual tramitación, en cambio la compra realizada mediante tarjeta de crédito requiere una reversa de la operación bancaria, que evidentemente le adhiere un mayor tiempo de espera.

En el caso de las operaciones por medio de tarjeta de crédito, tampoco existe un plazo fijo de espera, por tanto, el tiempo de espera en cada tienda es distinto. La particularidad aquí, según los entrevistados, es que el periodo de generación de la nota escapa al control de la tienda, pues es determinado por la casa comercial o banco operador de la tarjeta co-

${ }^{84}$ Esto es la regla general dentro de la garantía legal, que para el caso de la reparación incluye como sujeto pasivo al vendedor, y además al importador o al fabricante, ya sea conjunta o indistintamente. WILKINS (2019), p. 4.

${ }^{85}$ Se entiende por tal la definición otorgada por el SII, que señala que son "documentos que deben emitir los vendedores y prestadores de servicios afectos al IVA, por descuentos o bonificaciones otorgados con posterioridad a la facturación a sus compradores o beneficiarios de servicios, así como también por las devoluciones de mercaderías o resciliaciones de contratos". SII (2018). 
rrespondiente. La información recogida sitúa el tiempo de espera de la reversa entre los cinco a quince días hábiles.

\section{¿La devolución es realizada en caja? (f.15)}

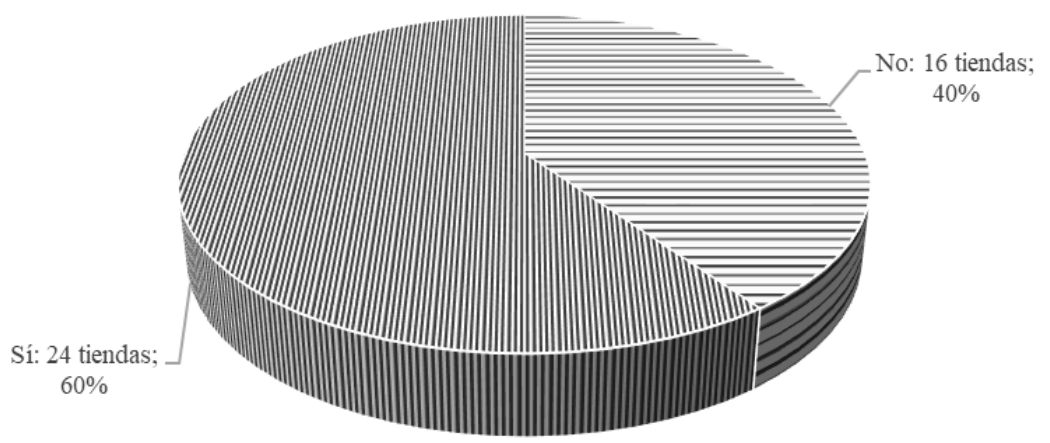

Todas estas circunstancias inciden en el tiempo efectivo que el cliente espera por la devolución de su dinero, que se suman a lo que el cliente ha debido soportar producto de la revisión del bien o la evaluación del servicio técnico, la autorización de la nota de crédito y otras instancias protocolares que configuran una mantención indeseada de la relación contractual que se pretende dejar sin efecto ${ }^{86}$, y durante todo ese periodo el consumidor no habrá podido acceder al dinero que le permitiría volver a acceder al bien.

El estudio identificó un número de veintiocho tiendas que realiza ventas mediante plataformas digitales, de las cuales solo nueve mantienen el mismo protocolo de las ventas físicas, en relación con poder hacer efectiva la garantía legal en cualquier tienda. En las otras diecinueve tiendas el protocolo de garantías es distinto, y la información es entregada a través de las mismas plataformas virtuales, al momento de efectuar la compra. Tan marcada es la diferencia de protocolos, que los vendedores de tienda reconocen no manejar información alguna del reembolso o cambio de productos comprados por internet.

También se preguntó a las tiendas por la existencia de un registro de cambios y devoluciones de dinero. Si bien muchas de ellas llevan un registro como parte de su información contable, según sus propias palabras,

${ }^{86}$ En dicho sentido se ha expuesto que la resolución es un mecanismo eficaz para el acreedor toda vez que permite al consumidor obtener lo que busca por una vía más adecuada, por ejemplo, celebrando un nuevo contrato con un tercero. En ese sentido véase Barros (2008b), p. 420; Peñailillo (2003), p. 395; Barrientos (2013), p. 537, confirmado en BARrientos (2016), p. 200. 
este no es de acceso al público general y, por tanto, no se pudo acceder a esta información. De todas maneras, sí señalaron montos estimados de devoluciones a nivel mensual o anual.

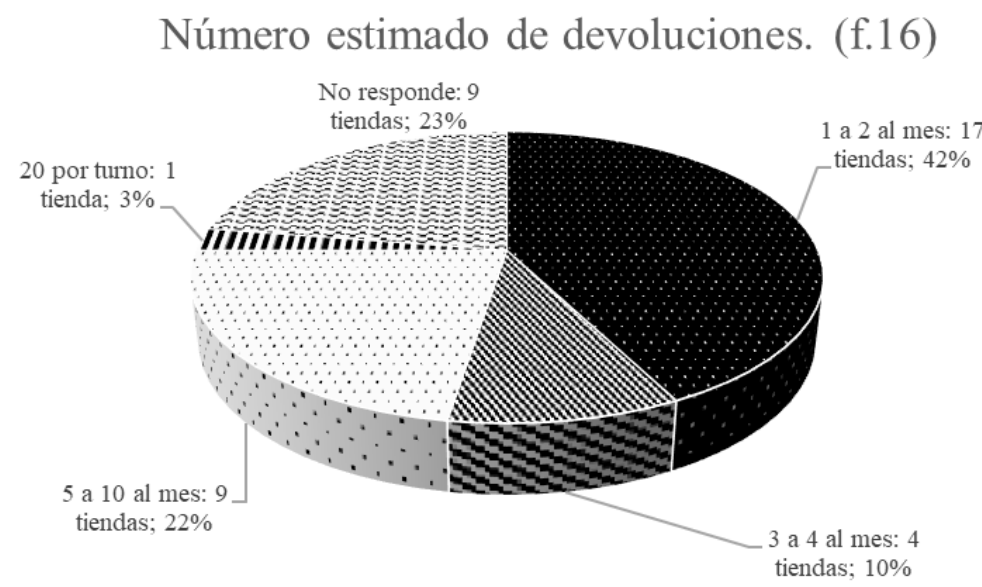

es mínima, diecisiete tiendas sostienen que mensualmente se hacen uno o dos, y en muchos casos los entrevistados advierten que hay meses en que ni siquiera uno.

Las multitiendas no responden a un estimado de reembolsos realizados periódicamente, pues los entrevistados no manejan esa información. Hacen estimaciones en torno a las diez devoluciones de dinero, debido a la gran cantidad de ventas que estas realizan, comparables, por ejemplo, con un supermercado entrevistado, el único lugar donde se registran veinte por turno (aun así, no se distingue si se hace por concepto de garantía legal o garantías voluntarias).

\section{Conclusiones}

Resulta un hecho que el derecho de reembolso en su fase extrajudicial no se manifiesta de manera uniforme, los datos obtenidos dan cuenta de que cada tienda articula de manera distinta la concurrencia de garantías $\mathrm{y}$, asimismo, el protocolo de petición tanto de la garantía legal como del reembolso.

De esta manera el consumidor que ha optado por ejercer su derecho producto de su disconformidad con el bien en una compraventa de con- 
sumo no cuenta con certeza respecto de cómo hacer valer su derecho, pues no existe una uniformidad en tal sentido, y a pesar de lo asegurado en la ley, muchas veces ni siquiera tendrá la posibilidad de optar por este remedio.

En primera instancia, como ha quedado de manifiesto en la revisión de las entrevistas, junto con la garantía legal es muy posible que concurran otras garantías o remedios ofrecidos por la tienda y, aunque existen casos en que ambas garantías coexisten de forma armónica, la experiencia recogida da cuenta de cómo las garantías convencionales finalmente limitan la garantía legal, llegando a impedir la elección del reembolso, lo que, sin duda, configura situaciones reales de desprotección.

Resolver la controversia existente en torno a que garantía debe primar al concurrir ambas, pese a desarrollarse en el ámbito judicial, pudiera otorgar claridad respecto a cuál es el alcance de la protección que la ley ha querido otorgar, y como deberá proceder en la práctica tanto el consumidor como el vendedor. En ese sentido se valoran los actuales esfuerzos realizados por los tribunales en virtud de ampliar la protección del consumidor $^{87}$, y algunos proyectos de ley como el Boletín n. ${ }^{\circ} 12409$, en especial en lo referido a propuestas modificatorias que ponen atención en cómo resolver este problema por la vía de la modificación del inc. $9^{\circ}$ del art. 15421 de la $\mathrm{LPC}^{88}$. Con ese cambio el criterio para solucionar el conflicto logra ser el de la mayor protección del consumidor, que es la esencia de la legislación de consumo.

En segunda instancia, también dentro de la garantía legal se producen conflictos, se ha constatado tal falta de uniformidad en la forma de articular la elección, que en ocasiones la libre opción no es respetada, sobre todo en la medida que la tiendas constante y abiertamente potencian, y en ocasiones imponen, la elección por el cambio y, en menor medida, la reparación, relegando al reembolso a situaciones de última opción, todo esto es contrario a la configuración de la garantía legal, que no sujeta la elección de alguna de sus opciones a ninguna condición, más que la elección del consumidor.

En tercera instancia, en lo que se refiere al reembolso en particular, los datos obtenidos dan cuenta de que este varía de tal forma y en tan

\footnotetext{
${ }^{87}$ En particular las cuatro posturas jurisprudenciales identificadas por Alfredo Ferrante que han evitado limitar la devolución del precio debido a la rigidez de la norma. En FERRANTE (2019b), p. 896 y ss.

${ }^{88}$ La propuesta modificatoria propone cambiar el inciso que ahora expresa: "Tratándose de bienes amparados por una garantía otorgada por el proveedor, el consumidor, antes de ejercer alguno de los derechos que le confiere el artículo 20, DEBERÁ hacerla efectiva ante quien corresponda y agotar las posibilidades que le ofrece, conforme a los términos de la póliza”, cambiando la palabra 'deberá' por la palabra 'podrá'. WiLkins (2019), p. 6.
} 
diferentes aspectos según las practicas definidas por las propias tiendas, que, en definitiva, el consumidor no tiene certeza de la forma en que debe solicitarlo extrajudicialmente, incluso de si puede optar o no por este. Es más, se pudo identificar de modo habitual la práctica, o estrategia comercial, de desincentivar el reembolso por parte de la tienda, ya sea indirectamente por medio de desincentivos visuales o de modo directo, haciendo del proceso de petición una cuestión engorrosa. E, incluso negando dicha posibilidad.

Tal nivel de control por parte de la tienda a través del establecimiento de garantías propias y de la aplicación de estrategias comerciales, termina siendo una verdadera barrera para el consumidor en el ejercicio de sus derechos, lo que es grave al tratarse de una garantía tan central en el derecho del consumidor como lo es la garantía legal.

Ante este panorama no puede olvidarse que la garantía legal y, en particular, el reembolso, miran hacia la protección al consumidor; cualquier interpretación que se haga en función del vendedor resultará forzada, pues atenderá a sus intereses y no a aquellos del consumidor, que es, en definitiva, la esencia de la normativa.

Se hace necesario un análisis y regulación más profundas y especializadas de la materia que resuelva las controversias jurídicas que pudieran indicar la forma en que debe articularse el reembolso en la fase extracontractual, a la vez que una intervención activa por parte de los organismos de protección al consumidor, que no se agoten en campañas publicitarias dirigidas a que él mismo reclame o ejerza sus derechos, sino que, dirigidas al control de las empresas vendedoras, con énfasis en la amplitud de su autorregulación, por medio de la fiscalización de los protocolos, como también del impacto de sus estrategias comerciales, de un modo tal que estas se adecuen a una protección amplia, aún más frente al actual desarrollo de nuevos tipos de comercio y la mayor complejidad en las relaciones de consumo que este conlleva ${ }^{89}$.

\section{BibLIOGRAFÍA CITADA}

BaraOna GonzÁlez, Jorge (2014). "La regulación contenida en la Ley 19.496 sobre protección de los derechos de los consumidores y las reglas de código civil y comercial sobre contratos: un marco comparativo". Revista Chilena

${ }^{89}$ Por ejemplo, la riqueza y complejidad del análisis de las compraventas a distancia y en línea, el incremento de las negociaciones en la web y la presencia preponderante de operaciones mediante crédito de dinero, han evidenciado el carácter obsoleto de la normativa de consumo, que fuera configurada en un diferente contexto. En tal sentido véase FERRANTE (2019b), p. 917. 
de Derecho, vol. 41, n. ${ }^{\circ}$ 2. Disponible en https://scielo.conicyt.cl/scielo.php? script=sci_arttext\&pid=S0718-34372014000200002\&lng=es\&nrm=iso\&tlng $=$ es [fecha de consulta: 22 de junio de 2018].

Barrientos Camus, Francisca (2011). "Comentario. Garantía legal o derecho de opción en el ámbito del consumo. Requisitos para que opere. Compatibilidad con la garantía convencional o garantía extendida del proveedor. Corte Suprema, 23 de marzo de 2011, y Corte de Apelaciones de Santiago, 30 de noviembre de 2010, rol 1700-2010”. Revista de Derecho Privado, n. ${ }^{\circ} 16$. Disponible en https://scielo.conicyt.cl/scielo.php?script=sci_arttext\&pid $=$ S0718-80722011000100012 [fecha de consulta: 22 de junio de 2018].

Barrientos Camus, Francisca (2013). "Una aproximación a la forma de incumplimiento que da lugar la garantía legal en las ventas reguladas en la Ley sobre protección de los derechos del consumidor". Revista de Derecho Universidad Católica del Norte, vol. 20, n. ${ }^{\circ}$ 2. Disponible en https://scielo.conicyt.cl/scielo. php?script=sci_arttext\&pid=S0718-97532013000200003 [fecha de consulta: 25 de junio de 2018].

Barrientos Camus, Francisca (2014). "La articulación de remedios en el sistema de la responsabilidad civil del consumo". Revista de Derecho de la Pontificia Universidad Católica de Valparaíso, vol. XLII, ${ }^{1 \mathrm{er}}$ semestre. Disponible en https://scielo. conicyt.cl/scielo.php?script=sci_abstract\&pid=S0718-68512014000100002\&ln $\mathrm{g}=\mathrm{es} \& \mathrm{nrm}=\mathrm{iso}$ [fecha de consulta: 26 de junio de 2018].

156 Barrientos Camus, Francisca (2016). La garantía legal. Santiago: Thomson Reuters.

Barros Bourie, Enrique (2008a). "La responsabilidad civil como Derecho Privado. Notas sugeridas por la reseña de C. Rosenkrantz al Tratado de Responsabilidad Extracontractual". Revista Estudios Públicos, n. ${ }^{\circ}$ 112. Santiago.

Barros Bourie, Enrique (2008b). "Finalidad y alcance de las acciones y remedios contractuales", en Alejandro GuZMÁn Brito (ed.). Estudios de Derecho Civil III. Santiago: Abeledo Perrot-Legal Publishing.

Corral Talciani, Hernán (1999). "Ley de protección al consumidor y responsabilidad civil. Derecho del consumo y protección al consumidor. Estudios sobre la Ley $\mathrm{N}^{\circ} 19.496$ y las principales tendencias extranjeras". Cuadernos de Extensión Jurídica, n. ${ }^{\circ}$ 3. Santiago.

Corral TAlCiani, Hernán (2006). "La responsabilidad por incumplimiento y por productos peligrosos en la Ley de Protección de los Derechos del Consumidor”, en Jorge Baraona González y Osvaldo Lagos Villaroel (eds.). $L a$ protección de los derechos de los consumidores en Chile. Aspectos sustantivos y procesales luego de la reforma contenida en la Ley $N^{\circ} 19.955$ de 2004. Santiago: Ediciones Universidad de Los Andes.

Corral TAlCiani, Hernán (2011a). "Relaciones entre la garantía legal y la garantía voluntaria del proveedor en la Ley de Protección de los Derechos de los Consumidores", en Fabián ElorRiaga de Bonis (coord.). Estudios de Derecho Civil VII (Jornadas de Derecho Civil Viña del Mar 2011). Santiago: Abeledo Perrot-Legal Publishing. 
Corral Talciani, Hernán (2011b). Responsabilidad por productos defectuosos. Análisis y propuestas para el derecho civil y el consumo en Chile. Santiago: Abeledo Perrot-Legal Publishing.

FEnoy Picón, Nieves (2006). El sistema de protección del comprador. Madrid: Colegio Nacional de Registradores.

Fernández Fredes, Francisco (1998). "Nueva Ley del Consumidor: innovaciones y limitaciones". Revista Perspectivas en Política, Economía y Gestión, vol. 1, n. ${ }^{\circ} 2$. Santiago.

Fernández Fredes, Francisco (2003). Manual de derecho chileno de protección al consumidor. Santiago: LexisNexis.

FERRANTE, Alfredo (2018a). “ ¿El contratante a tiempo compartido es consumidor? Avance crítico sobre la definición de consumidor chileno y ámbito objetivo de aplicación de la Ley". Revista Boliviana de Derecho, n. ${ }^{\circ} 26$. Disponible en www.revista-rbd.com/articulos/2018/26/438-467.pdf [fecha de consulta: 1 de diciembre de 2019].

FERRANTE, Alfredo (2018b). "El inicio del cómputo del plazo para el ejercicio de la responsabilidad Contravencional relativa a la Garantía Legal". Revista Chilena de Derecho Privado, n. ${ }^{0}$ 30. Disponible en https://scielo.conicyt.cl/pdf/rchdp/ n30/0718-8072-rchdp-30-0241.pdf [fecha de consulta: 1 de agosto de 2018].

FERRANTE, Alfredo (2018c). "Una revisión de los remedios del consumidor chileno en la compraventa con disconformidad a partir de la diferencia entre obligación y garantía". Revista de Derecho Privado, n. ${ }^{\circ} 35$. Disponible en www.scielo. org.co/scielo.php?script=sci_abstract\&pid=S0123-43662018000200165\&lng $=$ en\&nrm=iso\&tlng=es [fecha de consulta: 1 de agosto de 2018].

FERrante, Alfredo (2019a). "Consideraciones críticas sobre la resolución del contrato de venta de consumo frente a la disconformidad material en el derecho chileno", en Manuel Barria, José Luis Diez, Iñigo De la Maza, Rodrigo Momberg, Gonzalo Montory y Álvaro Vidal (dirs. y coords.). Estudios de derecho privado en homenaje al profesor Daniel Peñailillo Arévalo. Concepción: Thomson Reuters Legal Publishing Chile.

FERRANTE, Alfredo (2019b). "La jerarquía de remedios en la compraventa de consumo a partir de sus límites civiles y tributarios". Revista Chilena de Derecho, vol. 46, n. ${ }^{\circ}$ 3. Disponible en https://scielo.conicyt.cl/scielo.php?script=sci_arttext \&pid=S0718-34372019000300893 [fecha de consulta: 25 de abril de 2020].

Fuentes Weber, Melisa (2012). "El derecho de opción de la garantía legal en la Ley número 19.496”. Revista de Filosofía y Ciencias Jurídica, año I, n. ${ }^{\circ} 1$. Disponible en https://doctrina.vlex.cl/vid/derecho-opcion-garantia-legalley-19-426578050 [fecha de consulta: 15 de julio de 2018].

Isler Soto, Erika (2014). "Comentario de sentencia sobre el régimen de garantías derivado de la Ley N ${ }^{\circ}$ 19.496”. Ius et Praxis, vol. 20, n. ${ }^{\circ}$ 2. Disponible en https://scielo. conicyt.cl/pdf/iusetp/v20n2/art18.pdf [fecha de consulta: 15 de julio de 2018].

Jara Amigo, Rony (1999). "Ámbito de aplicación de la ley chilena de protección al consumidor: inclusiones y exclusiones”, en Hernán Corral Talciani. $D e-$ 
recho del consumo y protección al consumidor. Estudios sobre la Ley $N^{\circ} 19.496$ y las principales tendencias extranjeras. Santiago: Ediciones Universidad de los Andes.

MANQue TAPIA, Carlos (2006). Derecho del consumidor: responsabilidad civil por productos defectuosos en la Ley $N^{\circ} 19.496$ modificada por la Ley $\left.N^{\circ} 19.555\right)$ frente a una adecuada protección de los consumidores. Santiago: Editorial Librolex.

Marinakis Contreras, Francisca (2015). La garantía legal en la Ley $N^{\circ} 19.496$ Sobre Protección de los Derechos de los Consumidores: su relación con las garantías voluntarias y la responsabilidad civil derivada de su incumplimiento. Memoria de para optar al grado de Licenciado en Ciencias Jurídicas y Sociales. Santiago: Universidad de Chile. Disponible en http://repositorio.uchile.cl/bitstream/ handle/2250/136232/La-garant\%EDa-legal-en-la-Ley-no.-19.496-sobreprotecci\%F3n-de-los-derechos-de-los-consumidores.pdf?sequence $=1$ [fecha de consulta: 5 de julio de 2018].

Peñallillo Arévalo, Daniel (2003). Obligaciones. Teoría general y clasificaciones. La resolución por incumplimiento. Santiago: Editorial Jurídica de Chile.

PizArro Wilson, Carlos (2008). "La culpa como elemento constitutivo del incumplimiento en las obligaciones de medio o de diligencia". Revista de Derecho de la Pontificia Universidad Católica de Valparaíso, vol. xxxi, $2^{\circ}$ semestre. Disponible en https://scielo.conicyt.cl/pdf/rdpucv/n31/a05.pdf [fecha de consulta: 16 de julio de 2018].

Rodríguez Grez (2015). Derecho del consumidor. Estudio crítico. Santiago: Thomson Reuters.

SANDOval López, Ricardo (2009). La protección del consumidor y la libre competencia. Manual de Derecho Comercial. Santiago: Editorial Jurídica de Chile. Tomo I, vol. 1. 7a.

Vidal Olivares, Álvaro (2009). "La noción de incumplimiento esencial en el código civil". Revista de Derecho de la Pontificia Universidad Católica de Valparaíso, vol. XXXII. Disponible en https://scielo.conicyt.cl/pdf/rdpucv/n32/a06.pdf [fecha de consulta: 20 de julio de 2018].

\section{Jurisprudencia citada}

Briones Moreno con Automotores Gildemeister S.A. (2013): Corte de Apelaciones de Concepción, 5 de noviembre de 2013. Ing. 206-2013, cita en línea: CL/ JUR/2542/2013.

Franzani con Giuseppe Ltda. (2004): Corte de Apelaciones de Talca, 2 de enero de 2008, rol n. ${ }^{\circ}$ 66246-2004. Abeledo Perrot-Legal Publishing, nº 38139.

Irarrázaval con Antofagasta Store Co. S.A. Ripley (2008): Corte de Apelaciones de Antofagasta, 4 de julio de 2008, rol n. ${ }^{\circ}$ 39-2008. Abeledo Perrot-Legal Publishing n. ${ }^{\circ} 38750$.

Mella con Dunn F. y Dunn y García Ltda. (2006): Corte de Apelaciones de Concepción, 10 de agosto de 2006, rol n. ${ }^{\circ} 8190-2003$. Disponible en www.pjud. cl [fecha de consulta: 11 de septiembre de 2018]. 
Muñoz con Óptica Máster (2008): Corte de Apelaciones de Concepción, 11 de agosto de 2008, rol n. ${ }^{\circ}$ 606-2008. Disponible en www.pjud.cl [fecha de consulta: 28 de agosto de 2018].

Roth con Sociedad Rip Chile S.A. (2010): $2^{\circ}$ Juzgado de Policía Local de Viña del Mar, 23 de septiembre de 2010, rol 3102-10. Disponible en www.sernac. cl/proteccion-al-consumidor/registro-sentencias/buscador-historico/ [fecha de consulta: 29 de agosto de 2018].

Scheihing con París (2010): Corte de Apelaciones de Santiago, 30 de noviembre de 2010, rol n. ${ }^{\circ}$ 1700-2010. Disponible en www.pjud.cl [fecha de consulta: 20 de julio de 2018].

Scheihing con París (2011): Corte Suprema, 23 de marzo de 2011, rol n. ${ }^{\circ} 9357-$ 2010. Disponible en www.pjud.cl [fecha de consulta: 20 de julio de 2018].

Sernac con Almacenes París Comercial S.A. (2006): Juzgado de Policía Local de Huechuraba, 27 de junio de 2006, rol 72.622-Q-2005. Disponible en www. sernac.cl/proteccion-al-consumidor/registro-sentencias/buscador-historico/ [fecha de consulta: 28 de agosto de 2018].

Sernac con La Polar S.A. (2017): Corte Suprema, 31 de octubre 2017, rol 33.70717. Disponible en http://basejurisprudencial.poderjudicial.cl/ [fecha de consulta 11 de septiembre de 2018].

Sernac con Todo Piel S.A. (2011): Juzgado de Policía Local de Temuco, 29 de abril de 2011, rol 8847-M. Disponible en www.sernac.cl/proteccion-alconsumidor/registro-sentencias/buscador-historico/ [fecha de consulta: 29 de agosto de 2018].

Vera con Forus S.A. (2010): $1^{\text {er }}$ Juzgado de Policía Local de Valdivia, 9 de junio de 2010, rol 3084-2010. Disponible en www.sernac.cl/proteccion-al-consumidor/ registro-sentencias/buscador-historico/ [fecha de consulta: 29 agosto de 2018].

Walker con supermercado de muebles y colchones Speisky y Compañía Ltda. (2007): Corte de Apelaciones de Santiago, 21 de diciembre de 2007, rol n. ${ }^{\circ} 6273-$ 2007. Disponible en www.pjud.cl [fecha de consulta: 20 de julio de 2018].

\section{Normas citadas}

Código Civil de la República de Chile.

Ley n. ${ }^{\circ}$ 19496, Normas sobre Protección de los Derechos de los Consumidores. Diario Oficial de la República de Chile, Santiago, 7 de marzo de 1997.

\section{Documentos electrónicos citados}

Biblioteca del Congreso Nacional de Chile (1998). Historia de la Ley n. ${ }^{\circ} 19496$. Primer trámite constitucional, "Mensaje del Ejecutivo". Disponible en www. bcn.cl/obtienearchivo?id=recursoslegales/10221.3/619/1/HL19496.pdf [fecha consulta: 25 de junio de 2018]. 
GeoResearch (2014) Flujograma de visitas malls. Disponible en www.tecnomercadoretail.cl/plaza-vespucio-y-costanera-center-son-los-malls-con-mayorflujo-de-visitas/ [fecha consulta: 30 de junio de 2018].

Sernac (2012). Guía de alcances jurídicos Ley $\mathrm{N}^{\circ}$ 19.496. Disponible en www. sernac.cl/wp-content/uploads/2012/12/guia-de-alcances-juridicos-paraejercer-la-garantia-legal-sernac.pdf [fecha de consulta: 11 abril de 2018 - 26 de junio de 2018].

Sernac (2017a). Comportamiento de respuesta grandes tiendas comerciales con reclamos en el Sernac. Disponible en www.sernac.cl/wp-content/ uploads/2017/05/Ranking-Grandes-Tiendas-Comerciales-2017_12.05.2017. pdf [fecha de consulta: 11 de abril de 2018] y en www.SERNAC.cl/wp-content/ uploads/2017/05/2017.05.12-Comportamiento-grandes-tiendas-comercialesFINAL-EDITADA-POR-DN.pdf [fecha de consulta: 15 de junio de 2018].

SERnAC (2017b). Si el regalo del Viejito Pascuero presenta fallas, los consumidores tienen derecho a la garantía legal. Disponible en www.SERNAC.cl/ regalo-viejito-pascuero-presenta-fallas-consumidores-derecho-garantia-legalnavidad/ [fecha de consulta: 27 de julio de 2018].

SernaC (2019). Circular interpretativa de la Ley n. ${ }^{\circ}$ 21081. Disponible en https:// sernac.cl/postal/617/articles-9203_archivo_01.pdf [fecha de consulta: $11 \mathrm{de}$ noviembre de 2019].

SII (2018). Diccionario básico tributario contable. Disponible en www.sii.cl/diccionario_tributario/dicc_n.htm [fecha de consulta: 21 de agosto de 2018].

Transbank (2018). Medios de pago soluciones y servicios. Disponible en www. transbank.cl/web/productos-y-servicios/soluciones-medios-de-pago [fecha de consulta: 15 de junio de 2018].

Universidad Alberto Hurtado (2018). Directrices sobre el consentimiento informado. Disponible en www.uahurtado.cl/universidad/sobre-el-consentimiento-informado/ [fecha de consulta: 11 de abril de 2018].

Wilkins Binder, James (2019). "Garantía legal del consumidor. Marco regulatorio vigente y ejemplos en la legislación extranjera". Asesoría Técnica Parlamentaria. Disponible en /www.bcn.cl/obtienearchivo?id=repositor io/10221/27235/1/PL_Proteccion_Consumidor_GARANTIA_Comparado.pdf [fecha de consulta: 20 de abril de 2020].

\section{Sigla Y ABREVIATURAS}

$\begin{aligned} \text { art. } & \text { artículo } \\ \text { arts. } & \text { artículos } \\ C C & \text { Código Civil } \\ \text { Co. } & \text { Company } \\ \text { cons. } & \text { considerando } \\ \text { coord. } & \text { coordinador }\end{aligned}$


coords. coordinadores

dirs. directores

DL decreto ley

ed. editor

eds. editores

f. Figura

Fondecyt Fondo Nacional de Desarrollo Cien- $\frac{\Omega}{(\mathrm{D}}$ tífico y Tecnológico

http Hypertext Transfer Protocol

https Hypertext Transfer Protocol Secure

Ibid. Ibidem

inc. inciso

IVA Impuesto al valor agregado

LPC Ley n. ${ }^{\circ} 19496$ de Protección de los Derechos de los Consumidores

Ltda. limitada

n. ${ }^{\circ}$ a veces $\mathrm{N}^{\mathrm{o}}$ número

p. página

pp. páginas

S.A. sociedad anónima

Sernac Servicio Nacional del Consumidor

SII Servicio de Impuestos Internos

ss. siguientes

vol. volumen

www. World Wide Web 